\title{
Precios, salarios y nivel de vida de los trabajadores no calificados en Buenos Aires durante la primera mitad del siglo XIX
}

\section{Prices, Wages and Living Standards of Unskilled Workers in Buenos Aires During the First Half of the 19th Century}

\author{
Tomás Guzmán 1, * iD 0000-0002-2474-0412 \\ Roberto Schmit ${ }^{2,3}$ iD 0000-0003-4552-6391 \\ ${ }^{1}$ Instituto de Historia Argentina y Americana Dr. E. Ravignani, Universidad de Buenos Aires, Buenos Aires, Argentina. \\ ${ }^{2}$ Universidad Nacional de General Sarmiento, Buenos Aires, Argentina. \\ ${ }^{3}$ Consejo Nacional de Investigaciones Científicas y Técnicas, Buenos Aires, Argentina. \\ *Correspondencia: tguzman@filo.uba.ar
}

Resumen. En las últimas décadas, la historiografía latinoamericana se ha planteado múltiples preguntas y desafíos metodológicos sobre el problema del nivel de vida de las sociedades del continente en perspectiva histórica. El objetivo de este trabajo es abordar estos desafíos para el caso de la ciudad de Buenos Aires (Argentina) durante la primera mitad del siglo xIx. Utilizamos nuevas series de precios de una variedad de artículos de amplio consumo y de ingresos salariales de mano de obra de poca calificación (jornales de los peones albañiles y sueldos de empleados estatales de bajo rango). Con base en diversas canastas de consumo de subsistencia disponibles, presentamos diferentes posibilidades de series de salarios reales (welfare ratio). Así, examinamos la evolución del nivel de vida de los trabajadores no calificados porteños entre 1824 y 1850, durante un periodo de importantes transformaciones socio-económica y políticas.

CÓMO CITAR: Guzmán, T. y Schmit, R. (2022). Precios, salarios y nivel de vida de los trabajadores no calificados en Buenos Aires durante la primera mitad del siglo XIX. América Latina en la Historia Económica, 29(1), 1-27. DOI: 10.18232/alhe.1186 
Palabras clave: nivel de vida; precios; salarios reales; trabajadores no calificados.

Abstract. In recent decades, Latin American historiography has raised many questions and methodological challenges regarding the standard of living of the continent's societies in historical perspective. The aim of this paper is to address these challenges for the case of the city of Buenos Aires (Argentina) during the first half of the 19th century. We use new series of prices of a variety of items of wide consumption, and series of wage income of low-skilled labor (wages of bricklayers and salaries of low-ranking state employees). Based on various available subsistence consumption baskets, we present different possibilities of real wage series (welfare ratio). Thus, we examine the evolution of the living standards of unskilled workers in Buenos Aires between 1824 and 1850, during a period of important socio-economic and political transformations.

Key words: living standards; prices; real wages; unskilled workers.

JEL: N36.

Recibido: 24 de marzo de 2020

Aceptado: 27 de enero de 2021

Publicado: 04 de octubre de 2021.

\section{Los estudios históricos sobre el nivel de Vida en América Latina y el Río de la Plata}

En las últimas décadas ha cobrado renovado interés la historia de los niveles de vida de las sociedades, en el corto y en el largo plazos. Los trabajos de Robert Allen, y su propuesta metodológica, han promovido la temática, impulsándola a través de estudios comparativos globales (Allen, 2001; Allen, Bassino, Ma, Moll-Murata, y Van Zanden, 2011).

Para Latinoamérica, aquel interés cobra aún mayor significación, pues la región se caracteriza actualmente por la persistencia de sociedades muy desiguales y por un retraso en sus ritmos de crecimiento de los niveles de vida en relación con otros espacios. Por lo cual, aquel tipo de abordaje resulta pertinente para avanzar en el examen de las causas históricas de la evolución del bienestar material en América Latina. Asimismo, aparte de comparar los indicadores entre diferentes países, es relevante examinar el desarrollo diferencial del nivel de vida al interior de las naciones, y entre los diversos sectores sociales.

No obstante, a pesar de la importancia de disponer de estos estudios sobre la historia de los niveles de vida en nuestra región, los mismos han tenido una extensión dispar si nos referimos a las investigaciones que han planteado el problema desde la perspectiva del poder de compra de los salarios. ${ }^{1}$ Contamos con un conjunto variable de análisis comparativos generales y de largo plazo para el periodo colonial (Allen, Murphy y Schneider, 2012, 2015; Arroyo, Davies y Van Zanden, 2012; Dobado y García, 2014; Dobado, 2015) y luego para las décadas finales del siglo xix y el siglo xx (Astorga, Berges y Fitzgerald, 2005; Williamson, 1999). Por otro lado, tenemos pocos trabajos seriales que hayan enfocado en profundidad los complejos espacios y múltiples actores urbanos y rurales de las regiones americanas (Arroyo, 2013, 2014; Challú y Gómez-Galvarriato, 2015; Llorca-Jaña y Navarrete, 2015). El mosaico de las provincias del Río de la Plata (luego los estados de Argentina y Uruguay) es uno de los que comienza a ser investigado (Cuesta, 2012; Djenderedjian y Martirén, 2015; Gelman y Santilli, 2013, 2018; Johnson, 1990, 1992; Moraes y Thul,

${ }^{1}$ Además de los ingresos, existen otras dimensiones de los niveles de vida que también han sido exploradas, por ejemplo, el llamado bienestar biológico a través de los estudios antropométricos (Salvatore, Coatsworth y Challú, 2010). 
2018; Parolo, 2015, 2019). Por otro lado, destaca que han sido poco atendidas las economías latinoamericanas durante la época de "la larga espera", entre la crisis del orden colonial y la inserción en la primera globalización, según la expresión acuñada por Halperin (1992, pp. 140-212).

En gran medida, estos sesgos de la producción historiográfica han estado asociados a la escasa disponibilidad de fuentes homogéneas y confiables que nos permitan conocer, en detalle, la evolución de los precios de los principales bienes de consumo; las continuidades y cambios en las pautas de las canastas preferenciales de gasto de los núcleos familiares, y también, los variados tipos de ingresos, incluidos los salarios y jornales (en dinero y productos), percibidos por los trabajadores en diferentes tareas y ámbitos. Por ende, uno de los desafíos más patente es el metodológico, como han enfatizado Santilli y Gelman (2016) y Frid, Djenderedjian y Martirén (2018), para los casos rioplatenses, y Johnson y Tandeter (1992), para América Latina colonial.

Enmarcado en esta emergente historiografía, este artículo tiene como objetivo medir la evolución del nivel de vida de los trabajadores poco calificados en la ciudad de Buenos Aires durante la primera mitad del siglo xIx. Esta ciudad era el nodo primordial de la región económica rioplatense. Y fue centro de significativos cambios y de fases de auge y crisis socio-económicas durante aquel periodo. Por lo cual, nos proponemos contribuir a la evaluación del impacto que tuvieron aquellas transformaciones y coyunturas decimonónicas en el nivel de vida de los grupos sociales porteños.

Para alcanzar estos objetivos, encaramos un análisis serial de precios y salarios. En primer término, confeccionamos series de precios de productos esenciales de consumo popular, para una época de muy alta inflación y volatilidad. Asimismo, disponemos de series de salarios de mano de obra poco calificada de diferentes tipos de trabajadores: por una parte, los jornales de los peones albañiles y, por otra, los sueldos mensuales de empleados del Estado como vigilantes, porteros o cocineros. Con estas series, y con base en diversos tipos de canastas de consumo, para el periodo entre 1824 y 1850 , profundizaremos en varias posibilidades y comparaciones sobre la dinámica de los ingresos salariales reales, a través del indicador de la ratio de bienestar material (welfare ratio).

Para el caso de Buenos Aires, existe un grupo relativamente reciente de investigaciones históricas que ha estudiado sus niveles de vida. En un análisis pionero para fines del siglo XviII, Johnson $(1990,1992,2013)$ calculó series de salarios reales de trabajadores especializados y no especializados, combinando los precios de los alimentos y la vivienda con las series de salarios de peones y artesanos urbanos. Este autor mostró diferentes coyunturas del nivel de vida entre 1776 y 1815 y las vinculó con el crecimiento demográfico, la suerte de las cosechas y los eventos políticos.

En la última década, Gelman y Santilli $(2013,2018)$ han presentado otro conjunto de contribuciones sobre la evolución de los niveles de vida bonaerenses, entre la colonia y la primera mitad del siglo xIx. En uno de sus ensayos iniciales (2013), los autores abordaron el cambio del poder de compra de los salarios de los militares (soldados, cabos y capitanes), de los peones rurales (mensuales y diarios) y de los capataces, en términos de algunos bienes fundamentales del consumo popular (trigo, carne y azúcar). ${ }^{2}$ Plantearon que, a pesar del fuerte proceso inflacionario durante la primera mitad del siglo XIx, su efecto sobre el nivel de vida no habría sido tan negativo y señalaron la existencia de diversas coyunturas. En un primer momento crítico, de 1826-1828, no habría sucedido un fuerte estrés económico, sobre todo por un impacto diferencial y amortiguado que habría tenido el aumento de precios de los principales bienes de consumo. La situación habría

${ }^{2}$ Los salarios reconstruidos están analizados en Gelman y Santilli (2014). 
sido diferente entre 1838 y 1842, cuando la inflación sí habría disminuido el poder adquisitivo de los salarios de todas las categorías. Durante la década de 1840, la situación habría mejorado, aunque con diferencias según los tipos de trabajadores.

En estudios posteriores (Gelman y Santilli, 2018; Santilli, 2018), estos historiadores profundizaron el tema a través del uso de la metodología de canastas, mínima de subsistencia y "respetable", estandarizada por Allen. Con los datos proporcionados por fuentes hospitalarias y de otras instituciones religiosas y utilizando los salarios urbanos y rurales disponibles, calcularon ratios de bienestar para algunos años seleccionados (1796, 1806, 1818, 1819, 1825, 1835 y 1849), de forma tal de poder medir las variaciones en el nivel de vida y establecer una comparación internacional. Las conclusiones principales que postularon fueron, primero, que el bienestar material de Buenos Aires se situaba entre los más favorables de los diversos espacios de América y Europa para la época, lo que explicaría el atractivo inmigratorio de la región. En cuanto a la evolución temporal, Santilli (2018) planteó que, luego de una caída inicial entre 1796 y 1806, durante la primera mitad del siglo XIX el nivel de vida no habría sido perturbado seriamente. Pese al aumento de los precios de los productos cotidianos en la ciudad-puerto, el nivel de vida habría superado entre $20 \%$ a $40 \%$ el costo de la canasta "respetable". Al convertir esto al índice de welfare ratio (WR), para el peón albañil y su familia, habría significado que se pasase de una $W R$ de 2.05 para 1796, a 1.31 en 1806 , 1.38 en 1818, 1.21 en 1835, para incrementarse a 3.21 en 1849. Entonces, los datos mostrarían que durante este periodo se registraba un nivel de consumo aceptable, con un salto significativo a mediados del siglo.

Sin duda, los aportes mencionados ofrecen un soporte importante de evidencias y postulan un conjunto significativo de resultados. Considerando esta reciente historiografía, en este artículo revisitamos el problema de la evolución del nivel de vida para los trabajadores de baja calificación, con base en nuevas series de precios y salarios. También reexaminamos las canastas usadas por Gelman y Santilli y las analizamos con proporciones diferentes de bienes de consumo. Todo ello nos permitirá brindar un nuevo análisis serial anual de la welfare ratio para observar, en detalle, el efecto de los cambios producidos en los precios relativos y de diversos tipos de jornales y salarios urbanos. Asimismo, aquí nos enfocamos en la etapa de la primera mitad del siglo xix, la cual todavía no había sido examinada con esta precisión serial, a lo largo de sus principales coyunturas.

En la primera sección de este artículo ubicamos al lector en las características centrales que tuvo la economía porteña durante la primera mitad del siglo xix. Luego, en dos sendas secciones, analizamos los datos recogidos sobre precios y salarios, presentando las fuentes documentales, los métodos y las tendencias generales encontradas. En la cuarta sección, asentamos la metodología de elaboración de las canastas de consumo utilizadas. En la quinta, ofrecemos los principales resultados: las tendencias generales y los cambios coyunturales en el nivel de vida, para distintos tipos de grupos de trabajadores y con variaciones en la composición de las canastas. En las conclusiones discutimos estos resultados a la luz de los estudios previos y de las características del crecimiento económico bonaerense de la época.

\section{La economía de Buenos Aires en la PRIMERA Mitad del Siglo XiX}

La matriz económica posrevolucionaria de la provincia de Buenos Aires se sustentó en un avance sostenido, en diversas etapas, de su frontera rural, donde se expandió una renovada economía agroganadera de perfil exportador, que se complementaba con los servicios de la ciudad-puerto y las redes de transportes y comercio que la vincularon con las restantes provincias rioplatenses. 
Todo aquello sin perder la reproducción de una densa y extensa presencia de labradores y pastores, quienes participaron, en diferentes escalas y formas de explotación, de la estructura agraria bonaerense (Banzato, 2013; Djenderedjian, 2013).

El puerto de Buenos Aires incrementó su función como principal plaza mercantil rioplatense articuladora de un extenso espacio económico. La ciudad no sólo interconectaba su creciente hinterland rural con los mercados de ultramar, sino que acrecentó su papel de centro redistribuidor y de control de los negocios mercantiles, financieros y de servicios para los tratos de un amplio espacio mercantil que incluía a los mercados interregionales de las provincias del Litoral y del Interior. Esta participación se dio a través de la circulación de bienes de exportación derivados de la producción ganadera local y regional (cueros vacunos, tasajo y sebo), pero, sobre todo, con base en la lucrativa reventa de las mercancías ultramarinas (Halperin, 1982; Irigoin y Schmit, 2003; Rosal y Schmit, 2004). Este negocio importador proveyó a los porteños y a las otras provincias de una amplia gama de bienes de consumo básico popular, por ejemplo, la yerba mate, el azúcar, la harina, el tabaco y diversos tipos de textiles. Así se ha observado que las pulperías urbanas y rurales, establecimientos que abastecían diariamente a la población, aumentaron la participación de los bienes importados en sus stocks (Mayo, 1996, 2005; Wibaux, 2005).

El comercio resultó favorecido por un descenso importante del costo del flete trasatlántico, lo que dio una mayor rentabilidad a los bienes y aceleró los tratos intercontinentales. Pero también este fuerte vínculo abierto con los flujos del tráfico atlántico significó la emergencia de una nueva época de mayor incertidumbre, producto de los bruscos cambios coyunturales en los tratos y en los precios, generados por los ciclos de inestabilidad internacional. Estas fuerzas actuaron junto con el cambiante y conflictivo contexto político-institucional existente en la cuenca rioplatense luego de la revolución de independencia para profundizar la inestabilidad económica.

La función mercantil articuladora de largas distancias estuvo encadenada al dinamismo del mercado interno bonaerense. Las actividades orientadas a la provisión de ese mercado ocuparon a buena parte de la población trabajadora. En la zona rural, muchos productores se dedicaban al abasto de la ciudad-puerto, la cual consumía, para su provisión diaria y como insumos, un amplio conjunto de bienes agrícolas y ganaderos (Garavaglia, 1999). Este arrastre también llegaba a otras economías agrarias provinciales, que enviaban sus productos hacia Buenos Aires, aunque debieron competir con las importaciones. Otro conjunto de producciones era surtido por manufacturas básicas y artesanías instaladas en la plaza urbana (Johnson, 2013; Katz, 2017). La ciudad fue asimismo el epicentro de un entramado de servicios no transables, como las necesidades portuarias, de transporte, herramientas crediticias, la construcción, el comercio minorista y mayorista, los servicios domésticos y personales, y el aparato burocrático del Estado provincial (Guzmán, 2014). Estas actividades orientadas al mercado interno crecieron en el periodo, y tuvieron una articulación positiva con la expansión orientada por el comercio exterior (Brown, 2002, cap. 5).

Aquella expansión económica fue acompañada por un rápido crecimiento demográfico de la población tanto en la ciudad como en el área rural (aunque fue más veloz en la campaña). Durante el periodo aquí analizado, la tasa de crecimiento medio anual rondó, en la ciudad, un rango de 1 a $2 \%$ y, en la zona rural, de 3 a $4 \%$. La población de la provincia pasó de 110000 habitantes en 1822 a 271000 para el año 1854. En el caso de la ciudad, se incrementó de 55000 habitantes en 1822 a superar los 90000 en 1854 (Mateo, 2013).

En el plano fiscal, desde inicios del decenio de 1820, se promulgaron nuevas leyes sobre la recaudación impositiva y los aranceles de aduana. Sin embargo, el erario público prácticamente no gravó la propiedad ni los ingresos personales. En cambio, se acentuó la tradición colonial de 
sustentar los ingresos estatales en los recursos que proporcionaba el intercambio comercial. Es decir que los ingresos se movieron en correlación casi permanente con el cobro de los impuestos indirectos sobre el comercio, y en particular sobre los bienes importados (Irigoin, 2000, 2004; Schmit, 2013). Por lo tanto, este sesgo de las finanzas públicas acentuó el efecto de los ciclos comerciales y de la inestabilidad político-militar.

En efecto, existieron diversos ciclos de expansión y de dificultades económicas en la ciudadpuerto. Esos momentos estuvieron muy ligados con las actividades mercantiles afectadas por las guerras y los bloqueos navales al puerto (en 1826-1828, 1838-1840 y 1846-1848); con el creciente endeudamiento público, la emisión descontrolada de papel moneda inconvertible y los significativos costos inflacionarios en los bienes. También existieron otros ciclos de sequías y de parálisis productiva rural (Amaral, 1988, 1989; Djenderedjian, 2008, 2013; Garavaglia, 2004; Halperin, 1963, 1978, 1982; Schmit, 2013).

Pero, a diferencia de la nutrida evidencia de tipo cualitativa y cuantitativa serial en los estudios sobre los tópicos mencionados, según hemos visto, mucho menos conocemos acerca de cómo fue afectada la población en Buenos Aires en sus niveles de poder adquisitivo durante este periodo de expansión económica con fuerte volatilidad.

\section{LOS PRECIOS}

A partir de 1825, y durante la primera mitad del siglo XIX, los precios nominales de los bienes principales en el mercado porteño registraron una sostenida tendencia al alza. ${ }^{3}$ Pero, dentro de esa tendencia general, los bienes de consumo masivo tuvieron una gran diversidad de comportamientos en la evolución de sus precios relativos y en la notable volatilidad de sus registros (véase gráfica 1). Sobre todo, esto se debió al impacto desigual en los precios que generaron diversos factores, como los bloqueos comerciales, la emisión monetaria de papel moneda, la variación del nivel de demanda de los bienes y sus posibilidades de sustitución en la plaza (Schmit, 2016, 2019, 2020).

En cuanto a los bienes importados, más allá de la tendencia a largo plazo y las coyunturas volátiles, es necesario tener en cuenta que hubo una dinámica compleja. ${ }^{4}$ Entre ellos, los procedentes de las economías sudamericanas (la yerba mate, el azúcar y el arroz) fueron los que registraron los casos más extremos de inflación, con muy significativos incrementos y una gran volatilidad. Estos bienes tuvieron alta demanda y no tenían mucha posibilidad de sustitución en la plaza, por

${ }^{3}$ Las fuentes utilizadas son los registros de precios mayoristas corrientes publicados en la prensa, tomados de la Gaceta Mercantil y de la sección de precios del British Packett (colección de periódicos de la Biblioteca Nacional, sección Reservados, Buenos Aires). Recopilamos los precios de unos 35 productos del abasto del mercado porteño. Los mismos aparecen en general una vez a la semana, y con base en ellos se han calculado los precios promedios mensuales. Con esos datos posteriormente hemos calculado los diversos índices de precios que presentamos en la gráfica 1. En este apartado analizamos los siguientes precios: vino en pipa, sal en fanega, yerba en arroba, azúcar en arroba, arroz en arroba, galleta en barrica, fideos en arroba, tasajo por quintal, poroto en arroba, vela en arroba, trigo en fanega, maíz en fanega, carne en arroba, liencillo en yarda. En relación con la distancia entre los precios mayoristas y los del menudeo, tomamos una muestra de observaciones de varios productos de los avisos de los periódicos, y esa distancia no era significativa más allá de un rango de 3 a $5 \%$, que permite hacer los ajustes de los mismos sin grandes diferencias (Schmit, 2020).

${ }^{4}$ Respecto del peso de los bienes importados en el consumo doméstico porteño, hay diversas opiniones. Gelman y Santilli (2013) calculan ese peso en 20 \% sobre los consumos, en tanto Halperin (1982) y Burgin (1960) plantearon que el consumo habría sido más significativo. De todos modos, sostenemos que es necesario tener en cuenta dos pesos diferenciados sobre la evolución de su demanda. Uno fue el de los bienes importados sobre el consumo del amplio espacio mercantil ligado al puerto de Buenos Aires y otro el de los sectores populares de la provincia. 
lo tanto, se observaron súbitos incrementos a partir del bloqueo entre 1826-1828, y durante los decenios posteriores mantuvieron enormes oscilaciones y subas a causa de los bloqueos de 1838 1840 y 1846 - 1848. Desde la década de 1820-1830, el arroz tuvo varios incrementos, máximo de $1000 \%$, con un promedio final de $600 \%$. El azúcar subió máximo de $800 \%$ y promedio de $500 \%$. La yerba mate creció un tanto menos, con un promedio de $300 \%$. Luego, en la década de 1840, aquellos efectos volverían a incrementarse fuertemente durante los bloqueos, llegando al pico de $3500 \%$ el arroz, $4200 \%$ el azúcar y $2000 \%$ la yerba mate. Más tarde, esos productos volvieron a registrar fuertes oscilaciones y, en promedio, al final del periodo iban desde $1200 \%$ a 2000 por ciento.

En tanto los bienes importados desde otras plazas ultramarinas y de consumo generalizado como los vinos, el aguardiente, el aceite, los textiles, la sal, las harinas o los fideos- tuvieron menor nivel de demanda y de escasez, así como también podían tener sustitutos en el mercado local. Si bien sostuvieron una tendencia creciente, la misma fue menor, con oscilaciones diferentes, y con menos volatilidad coyuntural que los sudamericanos. Ellos fueron afectados igualmente por los problemas monetarios y por los bloqueos, pero, debido a la posibilidad de sustitución, estos factores tuvieron un impacto menor. Estos bienes registraban índices de incremento que iban desde un piso de $60 \%$ a un máximo de $220 \%$, al final del periodo, es decir que se trataba de subas generales muy inferiores respecto de efectos sudamericanos. La sal, el aceite, el vino y el aguardiente sostuvieron un aumento paulatino, a través de una larga tendencia más bien regular de incremento. En tanto otros como los textiles y las galletas tuvieron un incremento más cambiante, en forma regular escalonada, con alzas recortadas durante aquellos mismos años.

En relación con los productos locales, que eran esenciales en el abasto cotidiano del mercado de consumo bonaerense, hubo movimientos divergentes. Resultó significativa la suba sustancial del precio del trigo y del maíz, desde finales de la década de 1830, con una escalada que continuaría durante el decenio siguiente. Pese a la presencia de los numerosos labradores en la campaña porteña, el alza se habría debido a una evolución desigual entre la oferta de bienes, que no habría evolucionado de manera satisfactoria, y las necesidades de una demanda creciente de la población. Ello estaría relacionado con los pocos incentivos para volcarse a la producción agrícola y con la influencia, ya señalada por muchos estudios, de periodos continuos de sequías y de disturbios políticos en la provincia, que habrían afectado severamente la producción de granos (Djenderedjian, 2008).

En su valioso estudio sobre los precios de los bienes rurales, Garavaglia (2004) mostró las diferencias entre la marcha de los bienes agrícolas y los ganaderos. Mientras los precios de los granos subieron durante la década de 1840, los precios de las vacas -más allá del efecto coyuntural de los bloqueos - tuvieron una clara merma, que se debía, en buena medida, al crecimiento sustancial que tuvo por entonces la ganadería porteña, lo que también se correspondió con la inédita dinámica expansiva de las exportaciones pecuarias (Rosal y Schmit, 2004). Todo ello explicaría el control de precios del pan por el gobierno y la amplia oferta de carne, que era el principal bien de la canasta de consumo. De este modo, las tendencias del precio del trigo se despegaron por completo en su evolución respecto del precio de la carne, que permaneció estable, aunque registró leves y esporádicos aumentos hasta la mitad del siglo (Gelman y Santilli, 2013) (véase gráfica 1).

Aquella significativa inflación de los precios nominales y, sobre todo, la variación diferencial de los precios relativos resulta en insumos sustanciales para considerar el impacto complejo que habrían tenido sobre diferentes tipos de canastas de consumo posibles, durante las cambiantes coyunturas. 


\section{GRÁFICA 1. EVOLUGIÓN DEL ÍNDICE DE PRECIOS DE LOS PRINCIPALES PRODUCTOS. BUENOS AIRES, 1824-1850. AÑ BASE $=1824$}

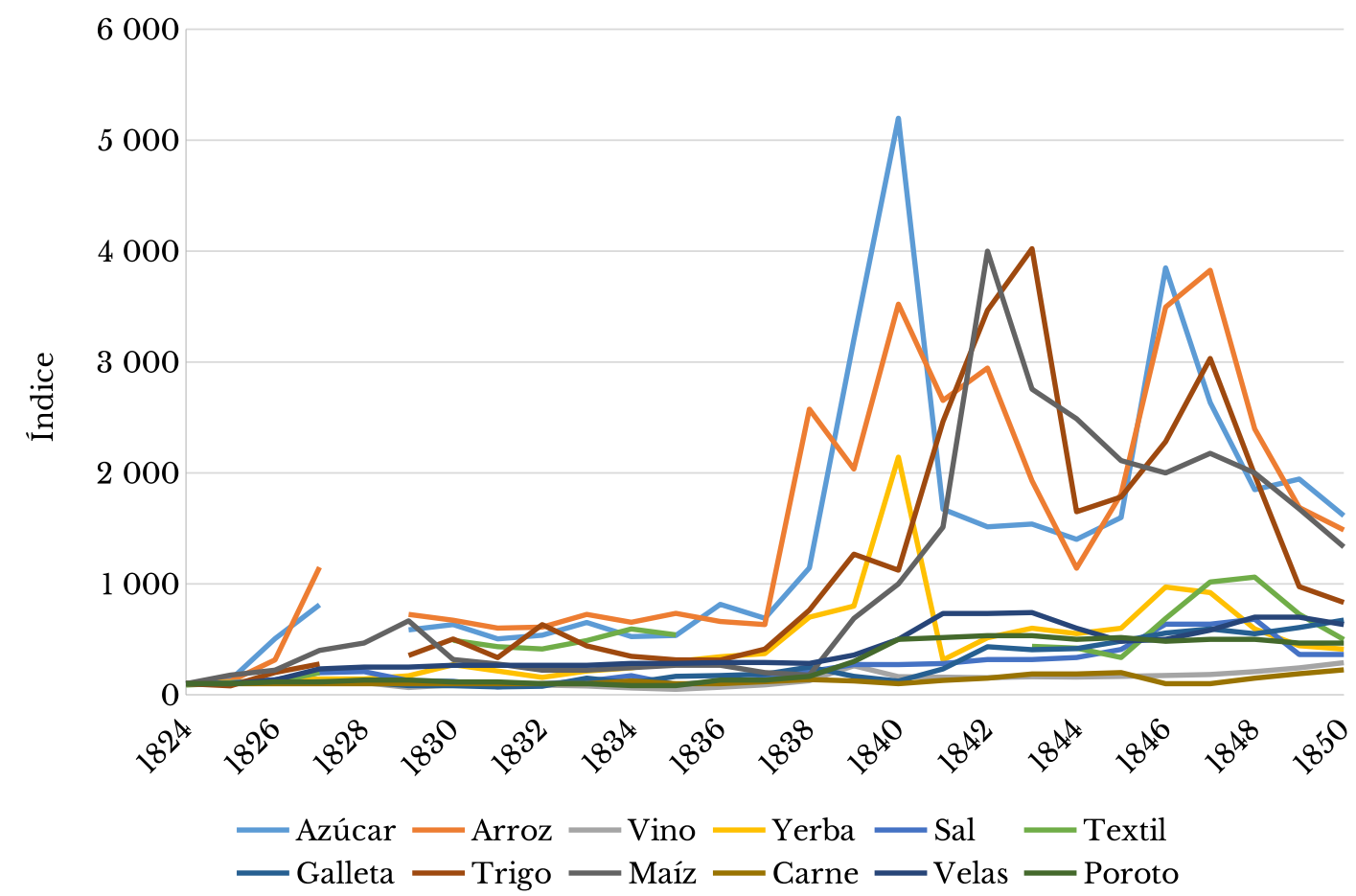

Fuentes: La Gaceta Mercantil y British Packett. Véase Schmit (2020).

\section{LOS JORNALES Y SUELDOS}

Para captar los ingresos de los trabajadores poco calificados, en este trabajo usamos dos categorías: a) los jornales de los peones albañiles, y $b$ ) los sueldos mensuales de trabajadores del escalafón inferior contratados por el Estado, como vigilantes de la policía urbana, cocineros y porteros.

La serie de jornales la construimos con los libros de cuentas de diversas dependencias estatales, en particular, los gastos hechos en obras de mantenimiento, refacción o ampliación de los inmuebles que ocupaban. Durante la primera mitad del siglo xIx, existieron pocas obras públicas de magnitud en la ciudad. Las restricciones fiscales del Estado posrevolucionario se hicieron sentir en este rubro (Aliata, 2006). Por lo tanto, no puede utilizarse la estrategia de los estudios de la época colonial que tomaron datos de las grandes obras como murallas, canales, edificios gubernamentales o eclesiásticos, las cuales duraron muchos años y ocuparon a muchos trabajadores (Johnson, 2013; Llorca-Jaña y Navarrete, 2015; Moraes y Thul, 2018).

Entonces, aquí recurrimos principalmente a la recopilación de aquellas tareas modestas de mantenimiento edilicio, que emplearon a grupos variables de trabajadores a lo sumo durante varios meses. No alcanza con tomar sólo una dependencia o establecimiento, dada la naturaleza irregular 
de este tipo de obras. Esto implica una revisión amplia de la contabilidad estatal. ${ }^{5}$ Si sumamos el impacto de los ciclos generales de la obra pública, se presentan dificultades para obtener observaciones suficientes para todos los años del lapso temporal definido. La cantidad de datos disponibles es más reducida para los periodos 1824-1827, 1838-1840 y 1846-1850. Para comenzar a salvar esta dificultad, recurrimos a una fuente secundaria: los datos dispersos de jornales de peones albañiles recolectados por Barba (1999, p. 182), que también provienen de los registros contables del estado provincial. La coincidencia entre ambas bases para la mayoría de los años en los cuales tenemos sendos datos resulta una buena guía inicial para completar los "huecos" existentes. ${ }^{6}$

Los jornales de peones que consignamos en la serie son los pagos monetarios diarios. ${ }^{7}$ No incluyen retribuciones no monetarias como comida u otros bienes (yerba o tabaco). De todas las planillas de pago consultadas, sólo unas pocas, en la década de 1820, aclaran explícitamente (con su valor o cantidad) la existencia de aquel tipo de compensación. Aunque la ausencia de esa práctica no puede llevarnos a descartarla, es posible que aquella "costumbre" fuese reduciéndose en el periodo.

Los albañiles y otros oficios específicos del sector de la construcción se organizaban en pequeñas empresas, que ejecutaban la construcción por encargo, bajo la conducción de algún maestrocontratista, con oficiales y peones jornaleros. ${ }^{8}$ La información disponible nos permite suponer que la mayoría de estos trabajadores eran asalariados libres. El predominio del salario como forma articuladora de las relaciones laborales era la tendencia en el mundo laboral urbano porteño de la primera mitad del siglo XIx (Salvatore, 2003, cap. 2). No obstante, como herencia de la organización laboral tardo-colonial, donde se mezclaban trabajadores libres y esclavos (Johnson, 2013, pp. 307-309), todavía hasta la década de 1830, habría habido una presencia de esclavizados en el sector. Por otra parte, en las obras públicas podían usarse trabajadores coaccionados, como presos y reclutas del ejército (Sábato y Romero, 1992, pp. 175-177), pero es difícil medir su incidencia efectiva a la vista de los registros consultados. Dentro de este proceso de formación del mercado de trabajo, los jornaleros albañiles pueden considerarse representativos de un vasto sector de trabajadores que vivían de un salario, poco calificados, con circulación espacial y movilidad entre patrones y actividades, y sujetos a pronunciados ciclos de ocupación, anuales y económicos. ${ }^{9}$

${ }^{5}$ La serie presentada es lo suficientemente sólida para avanzar con el análisis, pero preliminar en la medida que aún resta por indagar las rendiciones de cuentas de algunas dependencias, lo que nos permitirá a futuro fortalecer la base de datos. El grueso de los registros usados hasta ahora proviene del mantenimiento de los hospitales de la ciudad, del Parque de Artillería y de las obras de la Catedral. Guzmán (2018) ofrece detalles mayores sobre las fuentes y la metodología.

${ }^{6}$ Nuestra hipótesis es que los salarios pagados en la obra pública no deberían haber diferido sustancialmente de los provenientes de obras privadas, como construcción y reparación de edificios de vivienda o comercios, puesto que la mayor parte de las obras públicas se hicieron de manera descentralizada, en cabeza de un maestro-contratista, de forma similar a la operación privada.

${ }^{7}$ Dejamos de lado en esta ocasión los jornales, otros tipos de oficios de la construcción (como blanqueadores, pintores, carpinteros, etc.) y de otras categorías de clasificación (maestros, oficiales, sobrestantes, etcétera).

${ }^{8}$ Los trabajadores de la construcción (incluye fabricación de materiales de construcción) representaban alrededor de 4 \% de la población económicamente activa masculina (libre) en 1827, y $6 \%$ en 1855. Los datos son elaboración propia con base en una muestra de los censos poblacionales de esos años (Guzmán, 2014).

${ }^{9}$ Para una visión comparativa sobre el contexto laboral de los albañiles, Quiroz (2016) ofrece un detallado estudio de los trabajadores de las obras públicas en la ciudad de México entre 1687 y 1807. Stephenson (2018) enfatiza el valor de los estudios de historia social laboral para contextualizar adecuadamente los salarios, con referencia al mundo inglés del siglo XviII. 


\section{GRÁFICA 2. INGRESOS MENSUALES DEL PEÓN ALBAÑIL Y SUELDOS MENSUALES DE EMPLEADOS PÚBLICOS POCO CALIFICADOS. BUENOS AIRES, 1824-1850. AÑO BASE $100=1824$}

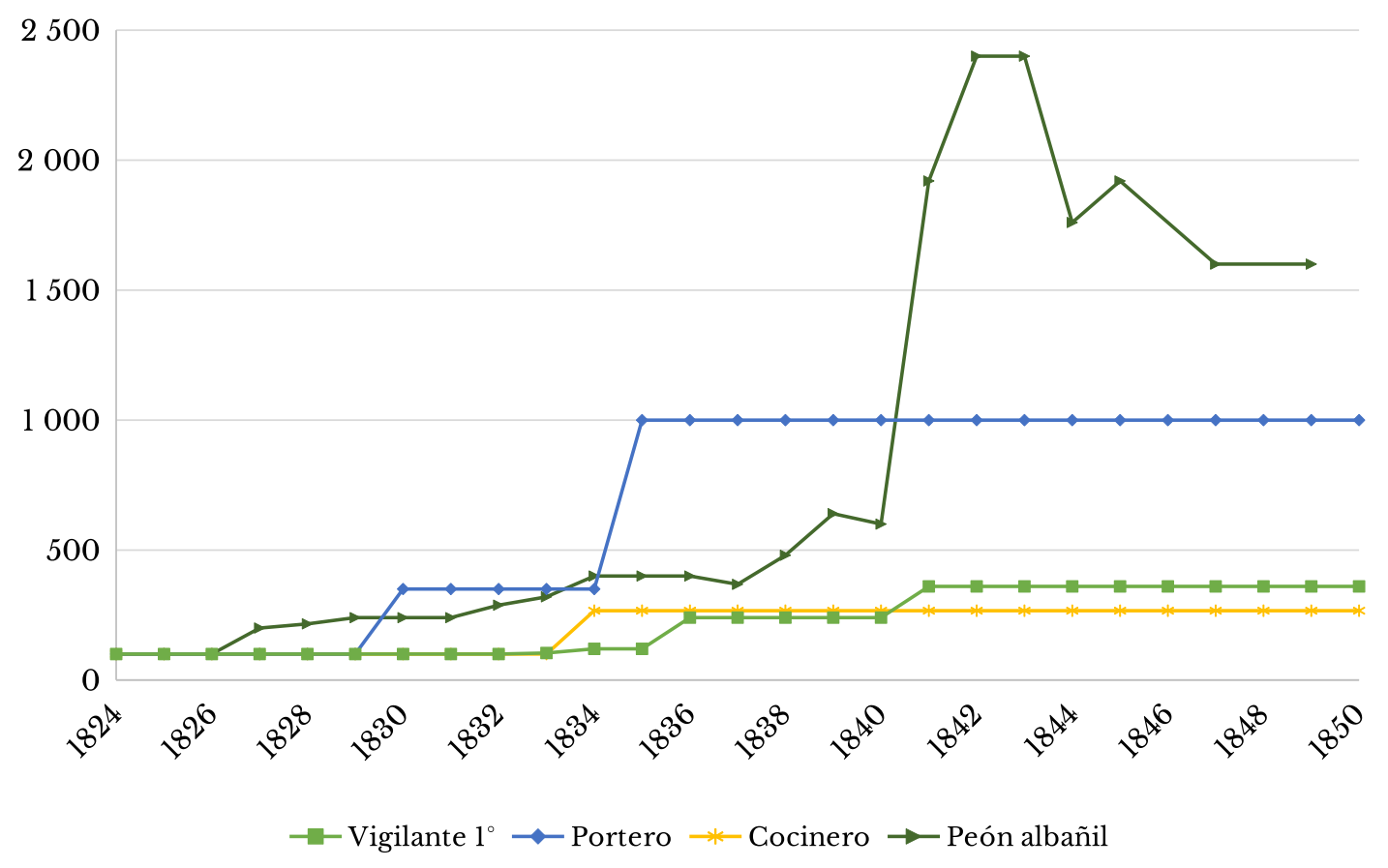

Fuentes: elaboración propia con base en Guzmán (2018) y Barba (1999).

Para disponer de un rango comparativo dentro de la estructura salarial de la ciudad, sumamos las series de los sueldos mensuales de empleados como vigilantes, cocineros y porteros, reconstruidas por Barba (1999). Este tipo de trabajadores formaba parte del heterogéneo mundo de los trabajadores poco calificados de la ciudad. En particular, los vigilantes de policía eran una figura frecuente entre los sectores populares. Los pagos a estos empleados policiales eran una parte significativa de la masa salarial del Estado provincial (Garavaglia, 2007, pp. 244-247, 354-358). Sus condiciones de contratación eran diferentes a las de los peones de la construcción. Tenían sueldos mensuales, que tendían a una mayor fijeza, así como contratos con perspectiva de permanencia y anudaban arreglos personales o de deferencia con sus empleadores. Es posible que recibieran complementos en forma de alimentos básicos como carne y verduras, y "vicios" como yerba y tabaco. No obstante, Barba no lo reporta, y por ende no lo consideramos para los cálculos.

$\mathrm{Si}$ mensualizamos los jornales de los albañiles, ${ }^{10}$ podemos comparar las series nominales de salarios que usaremos en lo que sigue (véase gráfica 2).

La evolución de los jornales en términos nominales muestra que tuvieron una relativa estabilidad en los primeros años de la serie. Los problemas monetarios y comerciales generados por la guerra de Brasil y el bloqueo naval de la ciudad impulsaron el alza de los jornales, que aumentaron

${ }^{10}$ Suponemos que los jornaleros trabajaban 250 días al año, esto es, 20.83 días de trabajo por mes. Este supuesto también lo usamos para calcular los ingresos anuales de los trabajadores, de acuerdo con la bibliografía de referencia (Allen, 2001). 
$140 \%$ entre 1826 y 1830 . Luego hubo una segunda fase de alza más moderada y estabilización (1831-1837). Etapa que terminó por los efectos de la gran crisis de 1838-1840 (bloqueo francés del puerto y recrudecimiento de las guerras civiles). Primero se observa una suba mesurada de los jornales hasta 1840 . Pero, a comienzos de la década de 1840 , los salarios nominales tuvieron un salto notable (de $200 \%$ entre 1839 y 1841). Este nuevo nivel logró mantenerse durante los años siguientes. Además, la volatilidad de los jornales parece haberse acentuado luego de 1840.

La evolución de los salarios de los trabajadores estatales es contrastante. Exhibieron una gran fijeza entre 1824-1829, en medio de las turbulencias. Los aumentos nominales llegaron después, en la década de 1830, a comienzos y a mediados de ella. Estos sueldos atravesaron inmóviles la gran crisis y permanecieron así hasta 1850 , en una época de fuerte movimiento ascendente de los precios. ${ }^{11}$ Lo más llamativo, sin duda, es el contraste entre esta estabilidad y el incremento de los jornales de los peones en los años de 1840, que superan a todas las otras categorías.

Hasta este momento presentamos la evolución de los precios y las series nominales de jornales y sueldos. La siguiente etapa es definir una canasta de consumo representativa de las preferencias de los trabajadores y usarla para medir el poder de compra de los ingresos salariales.

\section{LAS CANASTAS DE CONSUMO}

La canasta básica o mínima de subsistencia (bare bone basket) construida por Gelman y Santilli (2018) para Buenos Aires en la primera mitad del siglo XIx, es la mejor opción para encarar el análisis aquí propuesto, con adaptaciones derivadas de los datos seriados disponibles. Pero también adoptamos una versión modificada de esta canasta básica, así como otras provenientes de estudios generales (Allen et al., 2012; Arroyo et al., 2012). Este ejercicio tiene el propósito de evaluar la robustez de los resultados, como también de marcar las diferencias sobre el nivel de vida de acuerdo con diferentes propuestas de canastas en cuanto al predominio en ellas de los dos bienes alimenticios más importantes del consumo porteño: la carne vacuna y los derivados del trigo (pan). Por ende, confeccionamos canastas alternativas con mayor peso de la carne y otras con mayor peso del cereal.

\section{Canasta básica 1}

En la canasta de subsistencia 1, los rubros y los bienes son los establecidos por Gelman y Santilli para el año base de 1835 (véase cuadro 1). Esto permite realizar comparaciones con los datos relevados en dicha pesquisa, y a la vez ampliar la estimación del valor de la canasta a lo largo del tiempo. La principal sustitución que realizamos fue reemplazar el precio del pan por el del trigo. Para este cereal tenemos una buena serie anual de precios, pero no para el pan. Además, las políticas de abasto urbano suponían que, dado un precio fijo del pan, los consumidores recibían una hogaza cuyo peso estaba en relación inversa al precio de la fanega de trigo en el mercado. ${ }^{12}$ Asimismo, la serie de trigo permitiría captar la situación del autoconsumo de pan, amasado en los

${ }^{11}$ Expresadas las series en índice con base en el año 1824, las curvas de los salarios seleccionados muestran los diferentes puntos de partida. Pero en términos nominales, los sueldos mensuales de los trabajadores públicos terminaron siendo similares en la década de 1840, alrededor de los 90 pesos $\mathrm{m} / \mathrm{c}$.

${ }^{12} \mathrm{El}$ arancel establecido por la policía en 1834 indicaba que si la fanega de trigo valía 20 pesos, el real de pan blanco debía pesar seis onzas, mientras que si valía 40 pesos, el pan pesaría cuatro onzas. El Monitor, número 108, 25 de abril de 1834. Garavaglia (1999, pp. 264-265) describe el funcionamiento del arancel durante el periodo tardo colonial. 
hogares. Para hacer esta sustitución, calculamos la cantidad de trigo que daría un aporte calórico igual a la cantidad de pan que consideraron Gelman y Santilli en su canasta. Por otra parte, esta primera canasta respeta las cantidades consumidas anuales por persona y las conversiones en términos de calorías establecidos por estos autores.

CUADRO 1. CANASTA BÁSICA 1. BUENOS AIRES, 1824-1850

\begin{tabular}{|c|c|c|c|c|c|}
\hline & Unidad & $\begin{array}{c}\text { Cantidades } \\
\text { (anuales) }\end{array}$ & $\begin{array}{l}\text { Calorías } \\
\text { (diarias) }\end{array}$ & $\begin{array}{c}\text { Proteínas } \\
\text { (diarias) }\end{array}$ & $\begin{array}{l}\text { Porcentaje del } \\
\text { valor canasta } \\
\text { alimentos/total }\end{array}$ \\
\hline \multicolumn{6}{|c|}{ Alimentos } \\
\hline Trigo $^{\mathrm{a}}$ & $\mathrm{kg}$ & 26.38 & 245 & 9.89 & - \\
\hline Carne $^{\mathrm{a}}$ & $\mathrm{kg}$ & 232.38 & 1614 & 72 & - \\
\hline Vino $^{\mathrm{a}}$ & 1 & 4.79 & 11 & 0 & - \\
\hline Arroz $^{\mathrm{a}}$ & $\mathrm{kg}$ & 3.37 & 32 & 0 & - \\
\hline Grasa & $\mathrm{kg}$ & 1.57 & 38 & 0 & 2.5 \\
\hline Yerba & $\mathrm{kg}$ & s. d. & 0 & 0 & 6.6 \\
\hline Total & & - & 1940 & 82 & - \\
\hline \multicolumn{6}{|c|}{ Combustible, iluminación e higiene } \\
\hline Leña & - & - & - & - & 15 \\
\hline Velas & - & - & - & - & 15 \\
\hline \multicolumn{6}{|l|}{ Aceite } \\
\hline de lámpara & - & - & - & - & 15 \\
\hline Jabón & - & - & - & - & 2 \\
\hline \multicolumn{6}{|c|}{ Vestimenta } \\
\hline Lienzoa & $\mathrm{m}$ & 3 & - & - & - \\
\hline \multicolumn{6}{|c|}{ Vivienda } \\
\hline Alquiler & - & - & - & - & $5^{\mathrm{b}}$ \\
\hline
\end{tabular}

Notas: ${ }^{\mathrm{a}}$ Bienes con series de precios disponibles. ${ }^{\mathrm{b}}$ Adicionado sobre la canasta total.

Fuentes: elaboración propia con base en Gelman y Santilli (2018, tablas 7-9).

Contamos con precios para la mayoría de los bienes de esta canasta. Respecto de los ítems para los cuales no poseemos sus precios o no sabemos las cantidades consumidas, fue adicionado un porcentaje sobre el valor conocido de la canasta alimenticia (en el caso de la yerba, grasa, leña y jabón), o sobre la canasta total (para el alquiler). Estos porcentajes siguen la estructura de gastos de la canasta básica de 1835, y las proporciones estandarizadas en la bibliografía (es el caso del alquiler).

\section{Canasta básica 2}

Partimos de la canasta básica 1 y realizamos cambios, tanto en las cantidades de trigo y carne, como en la conversión del aporte calórico de algunos alimentos (véase cuadro 2). 
CUADRO 2. CANASTA BÁSICA MODIFICADA. BUENOS AIRES, 1824-1850

\begin{tabular}{|c|c|c|c|c|c|}
\hline & Unidad & $\begin{array}{c}\text { Cantidades } \\
\text { (anuales) }\end{array}$ & $\begin{array}{l}\text { Calorias } \\
\text { (diarias) }\end{array}$ & $\begin{array}{c}\text { Proteinas } \\
\text { (diarias) }\end{array}$ & $\begin{array}{l}\text { Porcentaje del } \\
\text { valor canasta } \\
\text { alimentos/total }\end{array}$ \\
\hline \multicolumn{6}{|c|}{ Alimentos } \\
\hline Trigo $^{a}$ & $\mathrm{~kg}$ & 26.38 & 489 & 19.7 & - \\
\hline Carne $^{\mathrm{a}}$ & $\mathrm{kg}$ & 52.68 & 1371 & 109.7 & - \\
\hline Vino $^{a}$ & 1 & 200.12 & 11 & 0 & - \\
\hline Arroz $^{\mathrm{a}}$ & $\mathrm{kg}$ & 4.79 & 34 & 0.7 & - \\
\hline Grasa & $\mathrm{kg}$ & 3.37 & 36 & 0 & 2.5 \\
\hline Yerba & $\mathrm{kg}$ & 1.49 & 0 & 0 & 6.61 \\
\hline Total & & s. d. & 1941 & 130 & - \\
\hline \multicolumn{6}{|c|}{ Combustible, iluminacion e higiene } \\
\hline Leña & - & - & - & - & 15 \\
\hline Velas & - & - & - & - & 15 \\
\hline $\begin{array}{l}\text { Aceite } \\
\text { de lámpara }\end{array}$ & - & - & - & - & 15 \\
\hline Jabón & - & - & - & - & 2 \\
\hline \multicolumn{6}{|c|}{ Vestimenta } \\
\hline Lienzoa & $\mathrm{m}$ & 3 & - & - & - \\
\hline \multicolumn{6}{|c|}{ Vivienda } \\
\hline
\end{tabular}

Notas: ${ }^{\mathrm{a}}$ Bienes con series de precios disponibles. ${ }^{\mathrm{b}}$ Adicionado sobre la canasta total. Fuente: elaboración propia con base en Gelman y Santilli (2018, tablas 7-9).

Mientras que en la canasta básica 1 predomina el aporte de la carne en la dieta, en esta segunda canasta, la carne sigue siendo fundamental, pero hay un poco más de peso del cereal. Es claro que, en una canasta de mínima subsistencia, en este contexto histórico, es lógico esperar el predominio de la carne, por ser la fuente más barata de energía y nutrientes. Sin embargo, aún a estos niveles de vida elementales, las preferencias de los consumidores tienen que ser consideradas. Conocemos el consumo extendido de pan y derivados de trigo que registran las observaciones de los contemporáneos y los estudios históricos (Eizykovicz, 2013, pp. 79-91; Garavaglia, 1999, pp. 252-266; Johnson, 1992, pp. 160-163). Si los precios relativos de la carne y el trigo-pan divergen, como sucedió en algunos periodos, resulta importante medir su efecto en el bienestar a través de canastas alternativas.

Por lo tanto, en la canasta básica 2, la principal modificación consistió en aumentar la cantidad de trigo consumida y reducir la cantidad de carne. Para ello se adoptaron los porcentajes de aporte calórico de trigo-carne de la canasta "respetable" de Gelman y Santilli y se proyectaron sobre 


\section{CUADRO 3. CONVERSIÓN CALÓRICA DE ALIMENTOS DE LA CANASTA BÁSICA}

\begin{tabular}{llrc}
\hline Bien alimenticio & Unidad & Calorias & $\begin{array}{c}\text { Proteinas } \\
\text { (gramos) }\end{array}$ \\
\hline Trigo $^{\mathrm{a}}$ & $1 \mathrm{~kg}$ & 3390 & 136.8 \\
Carne $^{\mathrm{b}}$ & $1 \mathrm{~kg}$ & 2500 & 200 \\
Vino $^{\mathrm{b}}$ & $1 \mathrm{l}$ & 850 & 0 \\
Arroz $^{\mathrm{c}}$ & $1 \mathrm{~kg}$ & 3650 & 71.3 \\
Grasa $^{\mathrm{d}}$ & $1 \mathrm{~kg}$ & 8823 & 0 \\
Yerba $^{\mathrm{d}}$ & $1 \mathrm{~kg}$ & 0 & 0 \\
\hline
\end{tabular}

Fuentes: a "Wheat Durum" (U.S. Department of Agriculture, 2019); b Allen (2001); c "Rice, white, long-grain, regular, raw, unenriched” (U.S. Department of Agriculture, 2019); d Gelman y Santilli (2018).

los de la canasta básica. ${ }^{13}$ Esto tiene como consecuencia que se dupliquen las cantidades de trigo consumidas y disminuyan en 16 \% las de carne. Así logramos un ajuste conservador, pues la carne sigue siendo el principal alimento por aporte calórico.

Por otro lado, frente a algunas discrepancias en los datos de traslación calórica de los alimentos que aparecen en diferentes bases de datos, decidimos revisar este aspecto y adoptar los factores de conversión que se detallan en el cuadro 3 . No obstante, las diferencias entre nuestra conversión de calorías respecto de la adoptada por Gelman y Santilli no son demasiado significativas, a excepción del kilo de arroz, para el cual calculamos $5.4 \%$ más calorías. Estos cambios determinaron algunas pequeñas modificaciones en las cantidades consumidas, para mantener constantes las $1941 \mathrm{kcal}$ diarias, de acuerdo con la metodología estándar.

\section{Otras canastas}

El tercer grupo de canastas fue construido siguiendo estudios previos de enfoque general para América Latina. Es el caso de la canasta realizada por Allen et al. (2012) para el periodo colonial latinoamericano (en particular las zonas andinas y mesoamericanas nucleares, como Potosí, Bogotá y México). Se trata de una canasta estándar, muy similar a la usada por Allen y otros autores para las comparaciones entre Asia y Europa. Tomamos este modelo, pero cambiamos el maíz por el trigo (según la equivalencia de aporte de calorías). Por otra parte, adaptamos la canasta "ArgentinaChile" de Arroyo et al. (2012), que, a diferencia de la anterior, tiene mayor peso de la carne. Para los precios faltantes, usamos los coeficientes provistos por los autores (véase cuadro 4).

13 Según el siguiente procedimiento: las cantidades de carne y pan originales de la canasta básica se modificaron, a las mismas cantidades de la canasta "respetable", para que sumasen (junto con el resto de los bienes de la canasta básica) un total de 1941 calorías. Finalmente se calculó la cantidad de trigo con el procedimiento ya explicitado. 


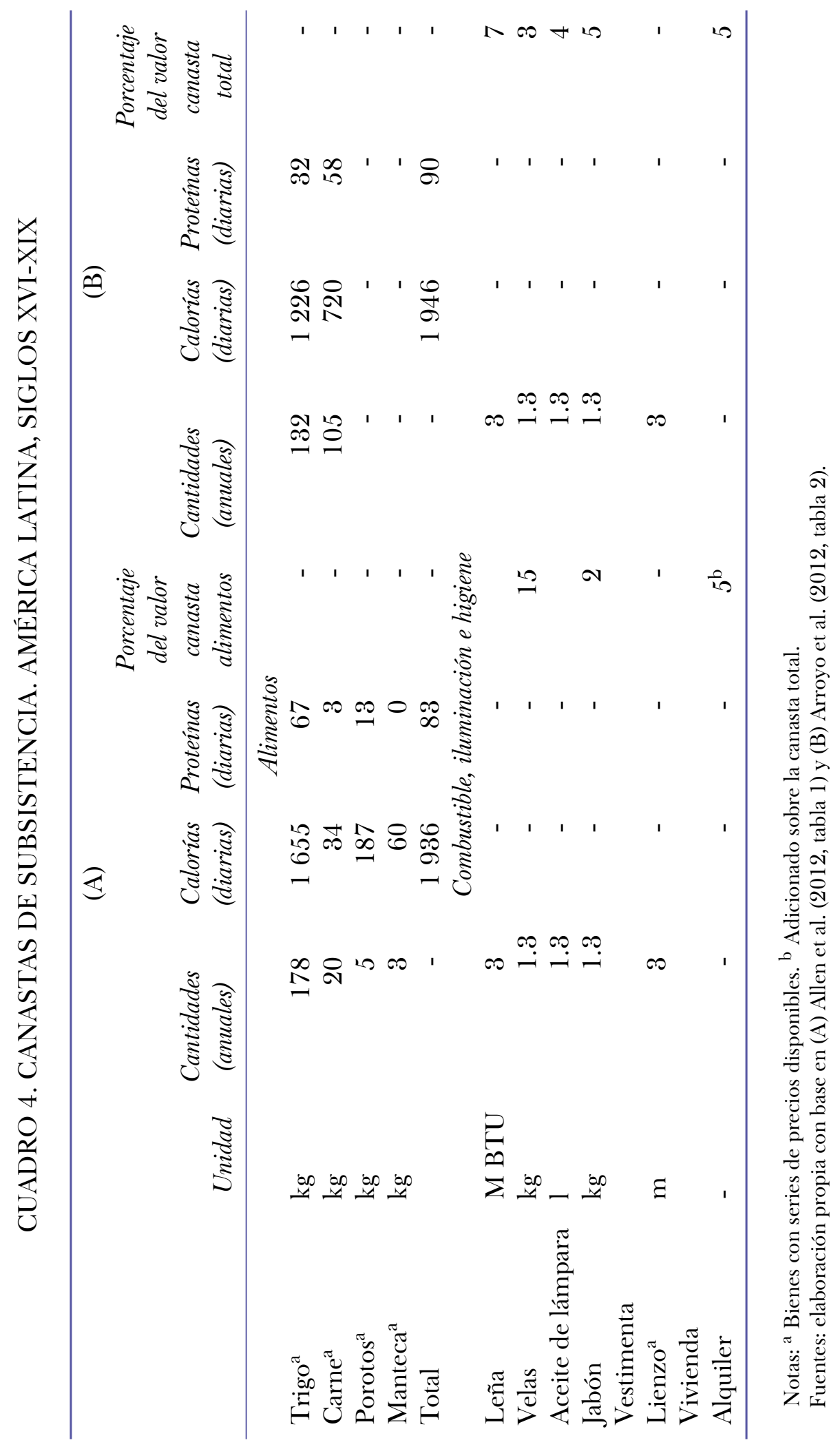


El Río de la Plata tenía la particularidad de ser una de las pocas regiones del mundo en la cual el mayor aporte de calorías y proteínas provenía de la carne vacuna. En la mayoría de otras canastas conocidas, tanto de América Latina, América del Norte, Europa y Asia, el principal componente siempre era un cereal o sus derivados. Por lo tanto, en una perspectiva comparativa, es interesante ver qué opción alternativa nos ofrece una canasta con mayor peso del trigo-pan.

En síntesis, tenemos una variedad de canastas para probar sobre los datos de precios y salarios, de manera tal de calcular salarios reales en diferentes escenarios (véase gráfica 3).

Hacia finales de la década de 1830, el precio del trigo inicia una tendencia alcista. Este movimiento genera una divergencia notable entre las canastas debido al peso relativo de este cereal en ellas (entre los extremos, de la canasta 1 a la canasta 3, basada en Allen et al., 2012). Esta brecha se va cerrando en los últimos años del periodo analizado. Veremos enseguida cómo impacta este proceso en el nivel de vida.

\section{EL NIVEL DE VIDA DE LOS TRABAJADORES NO CALIFICADOS}

Presentamos en la gráfica 4 los resultados de las ratios de bienestar (welfare ratios, WR) de los trabajadores no calificados: vigilantes, cocineros, porteros y peones albañiles. ${ }^{14}$ Es importante aclarar que todas estas $W R$ están calculadas sobre nuestra canasta modificada a partir de la elaborada por Gelman y Santilli (canasta 2).

Los jornaleros albañiles experimentaron sustanciales mejoras en su nivel de vida en el cuarto de siglo analizado, pasando de poder adquirir una canasta de subsistencia a poder comprar cerca de cinco. Mientras tanto, los trabajadores como vigilantes, cocineros o porteros, todos empleados a sueldo mensual de la administración pública, debieron sufrir, con ingresos bajos, los avatares del costo de la canasta básica. Al final del periodo, su nivel de vida, medido por la $W R$, no habría sido muy diferente del que tenían hacia 1824. Esto marcaría, por un lado, el poder de negociación de los jornaleros, sobre todo durante los periodos de aceleración del crecimiento de la economía bonaerense y, por el otro, la menor capacidad de los trabajadores estatales de bajo rango para evitar los efectos de los persistentes ajustes fiscales.

En cuanto al peso de las coyunturas críticas sobre la $W R$ fue una constante el efecto negativo de los bloqueos al puerto y la inflación de los precios sobre el nivel de consumo de los trabajadores. En orden de importancia, el deterioro fue mayor entre 1837-1839, algo menor en 1827-1828 y aún menor entre 1846-1847. Aquellos efectos desiguales también estarían ligados con la evolución disímil de los precios relativos de los bienes locales (cereales y carne) en los diferentes momentos en las canastas de consumo. Pero también es importante destacar que el resultado fue diferente según el tipo de trabajadores analizado. De modo que la inflación afectó mucho más al sector público bajo. Más indemnes salieron en cambio los trabajadores a jornal. Aunque también en estos se ven las caídas de la $W R$ en 1843 o 1847, debido al alza del precio del trigo.

${ }^{14}$ La ratio de bienestar (welfare ratio, WR) surge de dividir el ingreso anual del trabajador por el valor de la canasta para el consumo del trabajador y su grupo familiar. Para los ingresos anuales de los jornaleros estimamos 250 días de trabajo al año; para los empleados a sueldo mensual, multiplicamos este por doce. En cuanto al grupo familiar calculamos que se compone de una pareja de hombre y mujer adultos y dos hijos pequeños; cuya única remuneración proviene del trabajo del hombre. El gasto de consumo del trabajador adulto se multiplica por tres para computar el gasto familiar. Todos estos supuestos, sin duda debatibles, son los estandarizados tomando la propuesta original de Allen (2001). 


\section{GRÁFICA 3. VALOR DE LAS GANASTAS DE GONSUMO (POR PERSONA ADULTA). BUENOS AIRES, 1824-1850. AÑO BASE $100=1824$}

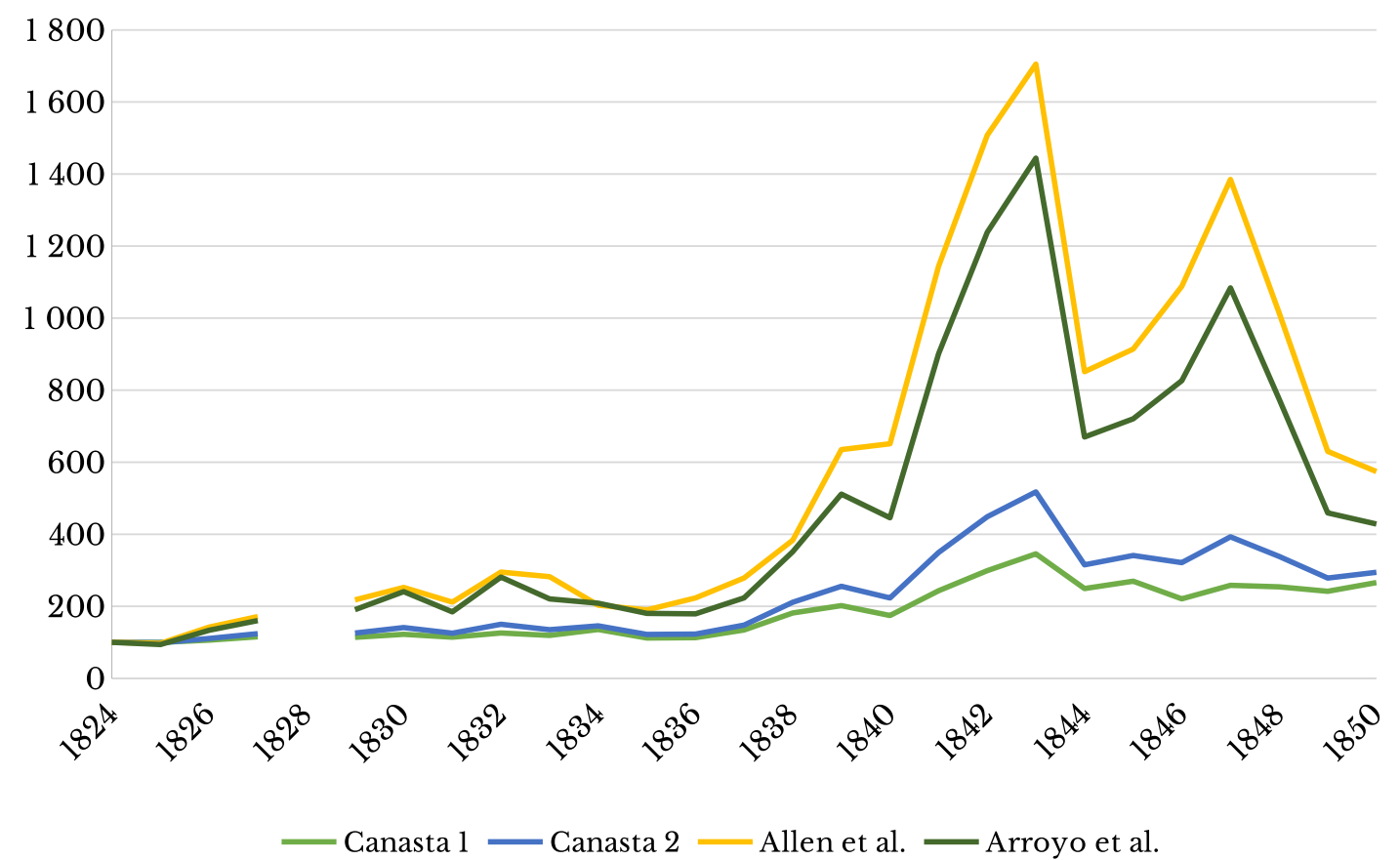

Fuente: Precios: La Gaceta Mercantil y British Packett; véase Schmit (2020). Composición de las canastas: elaboración propia con base en Allen et al. (2012, tabla 1); Arroyo et al. (2012, tabla 2); Gelman y Santilli (2018, tablas 7-9).

Las series nos permiten identificar claramente las coyunturas favorables o de aumento del nivel de vida. La época de mejores índices para el empleo público fue entre 1833-1837 y algo menos en 1848-1850. La primera coyuntura estuvo asociada con un periodo de alza de los salarios nominales que fue acompañada por precios estables o en ligera baja luego del cimbronazo de comienzos de la década. Sin embargo, no duró mucho esa "bonanza”, pues para los años de 1840 se había disuelto por el doble juego de la inflación y los ingresos salariales fijos. Por su parte, los peones albañiles jornaleros también compartieron esta mejora de mediados de los años de 1830, pero lo notable resultaría el aumento del estándar de vida alcanzado por los mismos en la década de 1840, cuando sus ingresos diarios subieron más velozmente que los precios. En efecto, es visible la tendencia similar hasta 1840, aproximadamente, y el posterior despegue del $W R$ del peón albañil.

A falta de un índice general de salarios, podemos observar la evolución general de las diversas $W R$, a través de la gráfica 5, que toma en consideración la franja de los mínimos, máximos y promedios de las $W R$ de trabajadores no calificados, asalariados y jornaleros. Se registra un rango de evolución que va desde 0.5 a 2 en la $W R$ inicial, con un pico de 3 a 5.5 en 1836, y luego una ampliación importante del rango entre 1.5 y 5 en los años de 1840. 
GRÁFICA 4. WR DE TRABAJADORES NO CALIFICADOS. BUENOS AIRES, 1824-1850

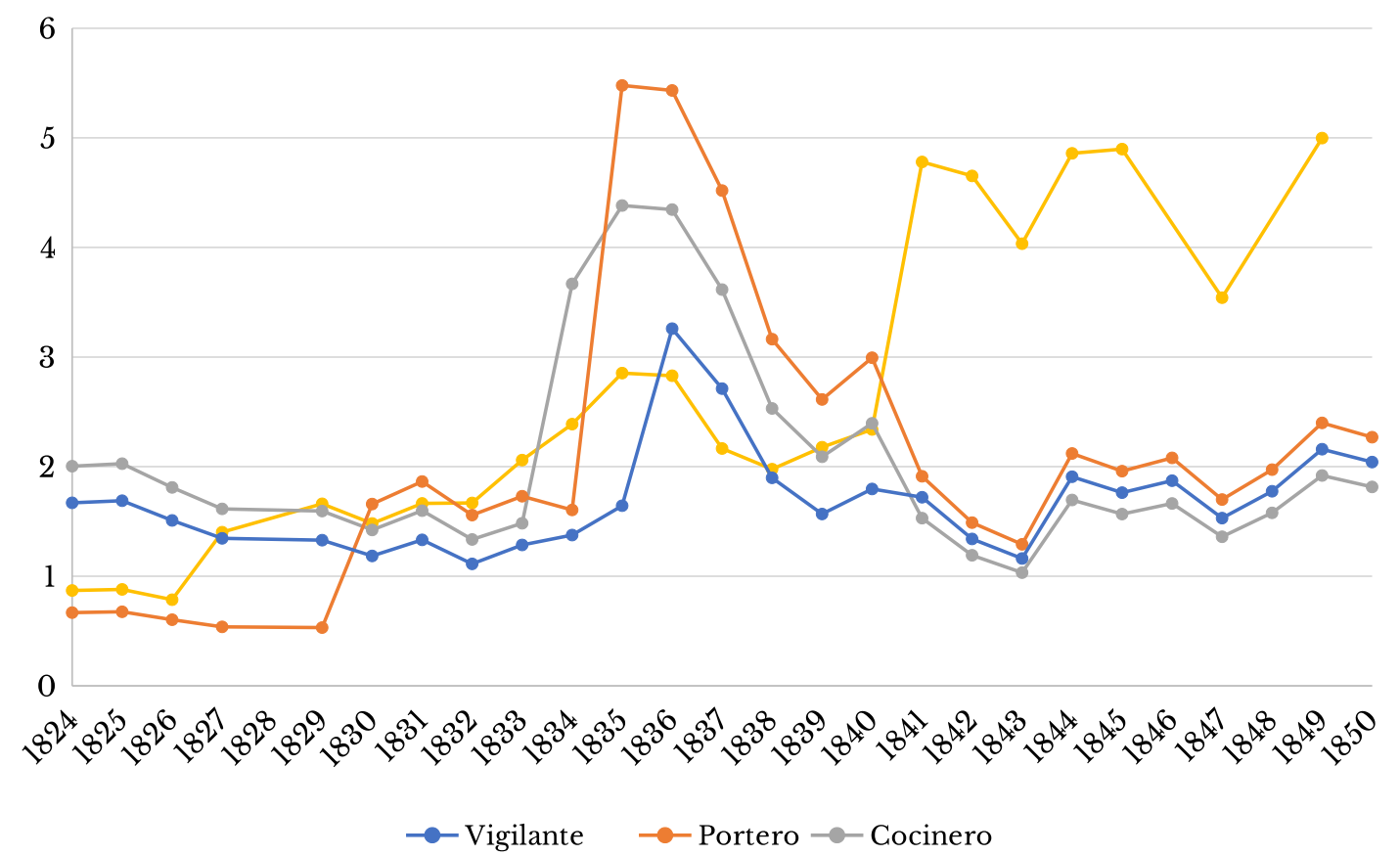

Fuentes: Precios: La Gaceta Mercantil y British Packett; véase Schmit (2020). Salarios: elaboración propia con base en Barba (1999) y Guzmán (2018). Composición de la canasta: elaboración propia con base en Gelman y Santilli (2018, tablas 7-9).

Se destacan dos momentos de aumento sustantivo de la WR (se duplican aproximadamente) en unos pocos años a mediados de la década de 1830 y a comienzos de la de 1840 . El primero fue un aumento general, también marcado entre los trabajadores estatales. El segundo fue exclusivo de los peones albañiles.

Una alternativa de observación de los cambios en las $W R$ son los promedios quinquenales de este indicador (véase cuadro 5). Vemos los picos que ya hemos destacado y la evolución general de cada una de las categorías. Frente a la sistemática progresión de la $W R$ para los jornaleros albañiles, la tendencia del nivel de vida de los porteros, cocineros y vigilantes está marcada por una mayor continuidad, sólo puntuada por la mejora del quinquenio 1834-1838.

Otra cuestión significativa es evaluar qué sucede si aplicamos las canastas alternativas para el cálculo de la ratio de bienestar. Aquí ofrecemos sólo los WR de los peones albañiles y los cocineros, por simplicidad y de acuerdo con lo analizado antes sobre los niveles y las tendencias comunes de los grupos (véanse gráficas 6 y 7).

$\mathrm{Al}$ considerar diferentes canastas el resultado evidente es la relativa semejanza de las WR alternativas hasta el año de 1838. De ahí en adelante, se abre una brecha. La clave de esa divergencia o abanico de niveles de $W R$ posibles está en el peso del trigo en cada canasta y el camino divergente de la carne y el trigo (pan), como bienes básicos de la dieta. Aunque el precio del trigo había sufrido las variaciones estacionales típicas del producto y una tendencia de aumentos importantes en las décadas de 1820 y 1830, fue en la década de 1840 cuando alcanza las cotas máximas. Mientras 


\section{GRÁFICA 5. MÍNIMO, MÁXIMO Y PROMEDIO DE LA $W R$ DE TRABAJADORES NO CALIFICADOS. BUENOS AIRES, 1824-1850}

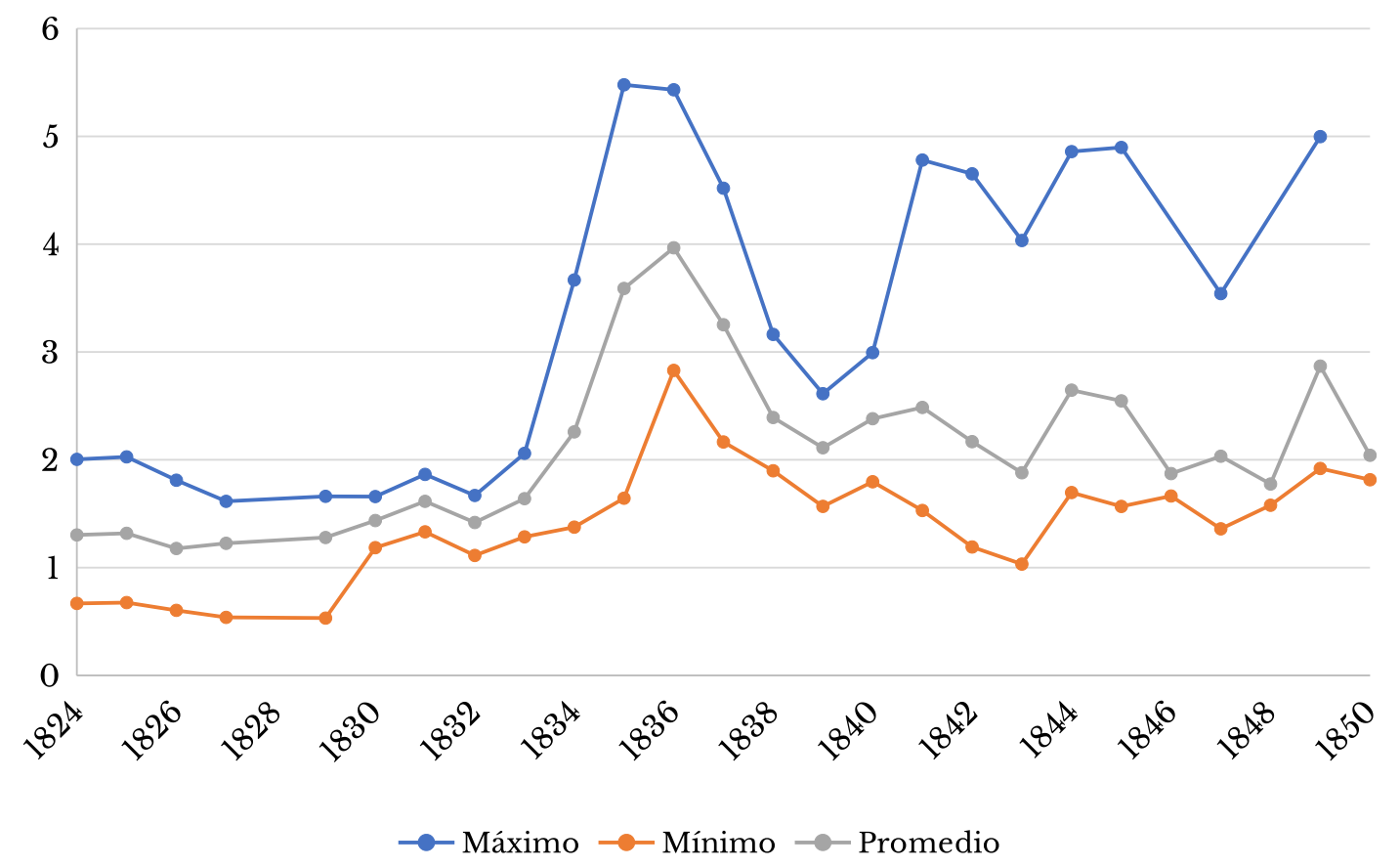

Fuentes: Precios: La Gaceta Mercantil y British Packett; véase Schmit (2020). Salarios: elaboración propia con base en Barba (1999) y Guzmán (2018). Composición de la canasta: elaboración propia con base en Gelman y Santilli (2018, tablas 7-9).

tanto, la carne mantuvo su estabilidad y bajo precio. El uso de una canasta con fuerte peso de la carne, como la utilizada por Gelman y Santilli, arroja las WR más elevadas. En tanto nuestra canasta preferida (canasta 2) sigue siendo predominante en carne, pero da mayor peso al trigo, por eso se ubica más cercana a aquella. En el otro extremo, una canasta básica basada sustancialmente en el aporte de cereal, como la de Allen et al. (2012) o Arroyo et al. (2012), nos daría una historia bastante diferente, que atenuaría significativamente los aumentos de ingresos de los peones albañiles y profundizaría el deterioro salarial de los trabajadores estatales de bajo rango. Debido a la magnitud que toman los ingresos anuales de los peones albañiles en la década de 1840, esta dispersión es más visible entre ellos que en el otro tipo de trabajador.

En suma, este ejercicio nos advierte sobre la necesidad de calibrar de forma cuidadosa la composición de las canastas para cada contexto. Como mencionáramos, las canastas dominantes en carne, como las rioplatenses, son excepcionales en los estudios comparativos internacionales. Si aplicáramos unas canastas similares a las de esos estudios generales, la imagen de los niveles de vida sufriría cambios evidentes. La posibilidad de contar con una oferta accesible de carne vacuna marcó una gran diferencia favorable para los trabajadores en la amplia región rioplatense. ${ }^{15}$

15 Frid, Djenderedjian y Martirén (2018) argumentan de manera similar para la provincia de Santa Fe, en la región pampeana de Argentina. El factor de la carne barata como una característica significativa rioplatense también podría explicar, en parte, los resultados observados en Montevideo por Moraes y Thul (2018). 


\section{CUADRO 5. WR DE TRABAJADORES NO CALIFICADOS. PROMEDIOS QUINQUENALES. BUENOS AIRES, 1824-1848}

\begin{tabular}{llllll}
\hline & $1824-1828$ & $1829-1833$ & $1834-1838$ & $1839-1843$ & $1844-1848$ \\
\hline Portero & 0.62 & 1.47 & 4.04 & 2.06 & 1.97 \\
Cocinero & 1.86 & 1.49 & 3.71 & 1.65 & 1.57 \\
Vigilante & 1.55 & 1.25 & 2.18 & 1.52 & 1.77 \\
Peón albañil & 0.98 & 1.71 & 2.44 & 3.6 & 4.43 \\
\hline
\end{tabular}

Fuentes: Precios: La Gaceta Mercantil y British Packett; véase Schmit (2020). Salarios: elaboración propia con base en Barba (1999) y Guzmán (2018). Composición de la canasta: elaboración propia con base en Gelman y Santilli (2018, tablas 7-9).

También esto es importante para el análisis temporal más amplio, pues la canasta propuesta por Johnson (1992) para el periodo tardo-colonial es intensiva en trigo. Sin duda, como ya advirtieron estudios anteriores (Gelman y Santilli, 2013), debieron de existir, para los periodos colonial y posindependiente, diversos tipos posibles de sustituciones entre ambos productos en los patrones de consumo de los trabajadores con bajos ingresos.

\section{Conclusiones}

En este artículo sostenemos que el nivel de vida de los trabajadores poco especializados no tuvo una trayectoria negativa en Buenos Aires durante la primera mitad del siglo XIx. Nos hemos referido aquí al nivel de vida medido por los ingresos salariales contra un parámetro elemental, una canasta de subsistencia mínima. En futuros trabajos, resta explorar el problema con canastas más exigentes en cantidad y calidad de bienes (llamadas respetables en la metodología de Allen), e introducir, si es posible, mayor complejidad desde el lado de los ingresos (otros ingresos no salariales, de otros miembros del hogar, etcétera).

Estos resultados van en línea con las descripciones de observadores y viajeros contemporáneos que señalaban la relativa facilidad en el acceso a los alimentos, y los altos salarios nominales de los trabajadores (Barba, 1967). El contexto estructural de una economía en expansión, todavía "de frontera”, con una dotación de factores abundante en tierra y escasa en trabajo y capital, también resulta coherente con lo analizado, aunque ahora contamos con medidas más precisas que nos permiten mostrar una situación con matices. En efecto, se trató de una época marcada por una inflación elevada y por un conjunto de transformaciones económicas y político-institucionales, que generaron diferentes vaivenes coyunturales y fuerte volatilidad de las variables, incluidos los precios y salarios. A pesar de ello, los niveles de ingresos reales de los diversos tipos de trabajadores, en términos de los índices de welfare ratio, no disminuyeron respecto de los registrados a comienzos de la etapa examinada. En otros términos, el crecimiento económico del periodo fue compatible con una mejora o mantenimiento de los niveles de vida de los trabajadores de baja calificación.

Esta evaluación es coincidente con los estudios previos para el espacio bonaerense, pero si comparamos nuestro análisis serial de la $W R$ con aquellos encontramos diferencias importantes para comprender la evolución del estándar de vida en función de: la canasta utilizada, del tipo de trabajador analizado y de los años que se consideren. 


\section{GRÁFICA 6. WR DE LOS PEONES ALBAÑILES CON CANASTAS ALTERNATIVAS. BUENOS AIRES, 1824-1850}

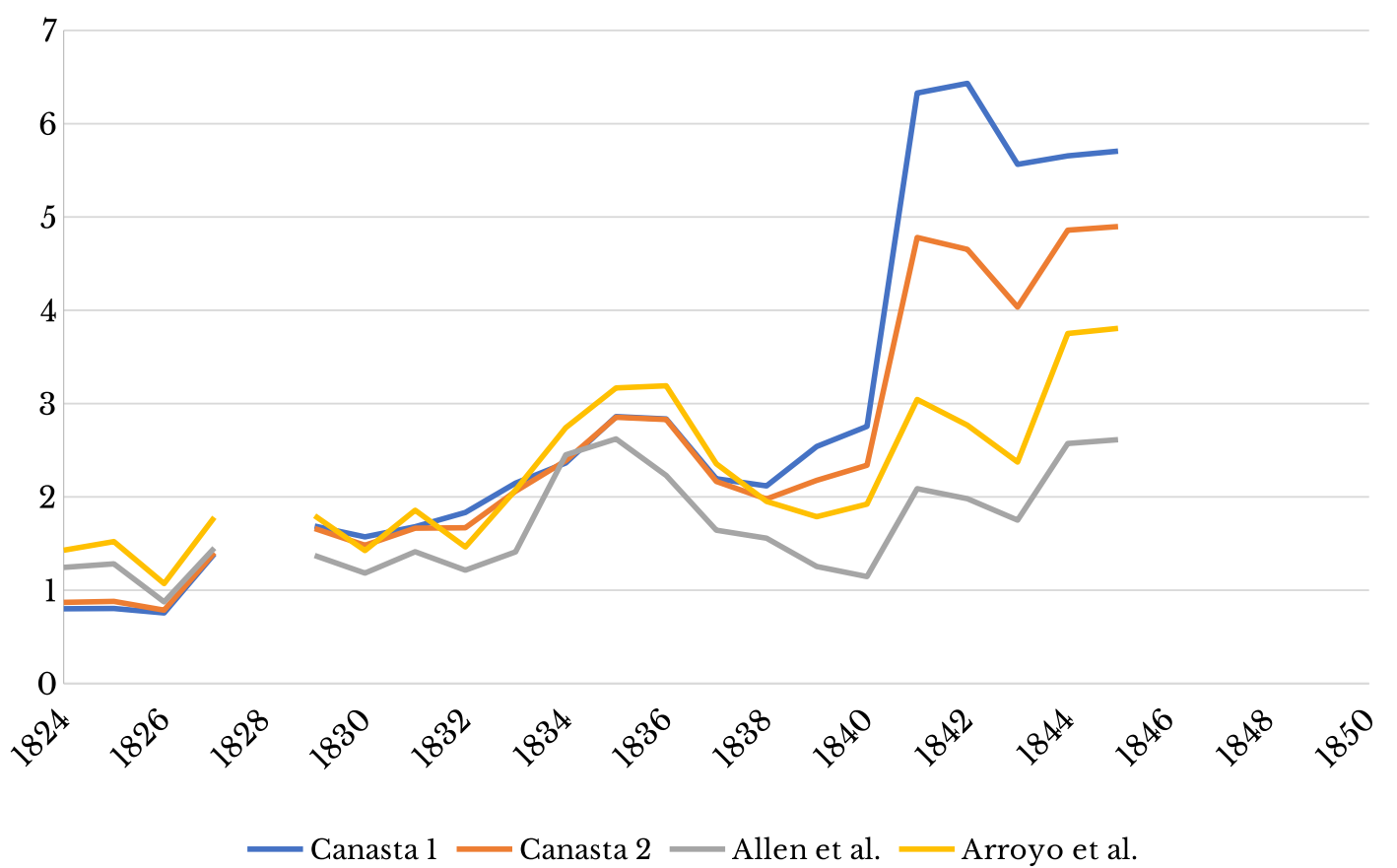

Fuentes: Precios: La Gaceta Mercantil y British Packett; véase Schmit (2020). Salarios: elaboración propia con base en Barba (1999) y Guzmán (2018). Composición de la canasta: elaboración propia con base en Gelman y Santilli (2018, tablas 7-9), Allen et al. (2012, tabla 1) y Arroyo et al. (2012, tabla 2).

Respecto de la canasta de consumo hemos mostrado que, para este caso de estudio, el tipo de composición de la canasta, basada fundamentalmente en carne o cereales, afecta de manera desigual la evolución de los registros. Ello se relaciona con unos bienes que podían ser sustitutivos, en ciertos márgenes, pero cuyos precios evolucionaron de manera diferente. Por lo cual se explica que, a pesar de tratarse de un periodo inflacionario, el acceso abundante y permanente, a bajo costo, a la carne, que funcionó como el bien de subsistencia de equilibrio, fue un factor central para comprender la trayectoria favorable del bienestar material durante la primera mitad del siglo XIX.

También resulta sumamente significativo destacar las diferencias observadas según las categorías de trabajadores, aun moviéndonos sólo dentro del mundo de los no calificados, como asimismo considerar la dinámica de los cambios coyunturales. Así, las WR de trabajadores no especializados estatales muestran una tendencia de crecimiento modesta, con un avance sobre todo en el lapso de 1834-1838, para luego sufrir una fuerte caída entre 1839-1843, y retomando, en parte, una leve recuperación en el último periodo considerado. En tanto los jornaleros albañiles tuvieron un crecimiento constante del nivel de vida, con un incremento sustancial en la década de 1840 . 


\section{GRÁFICA 7. WR DE LOS COCINEROS CON CANASTAS ALTERNATIVAS. BUENOS AIRES, 1824-1850}

6

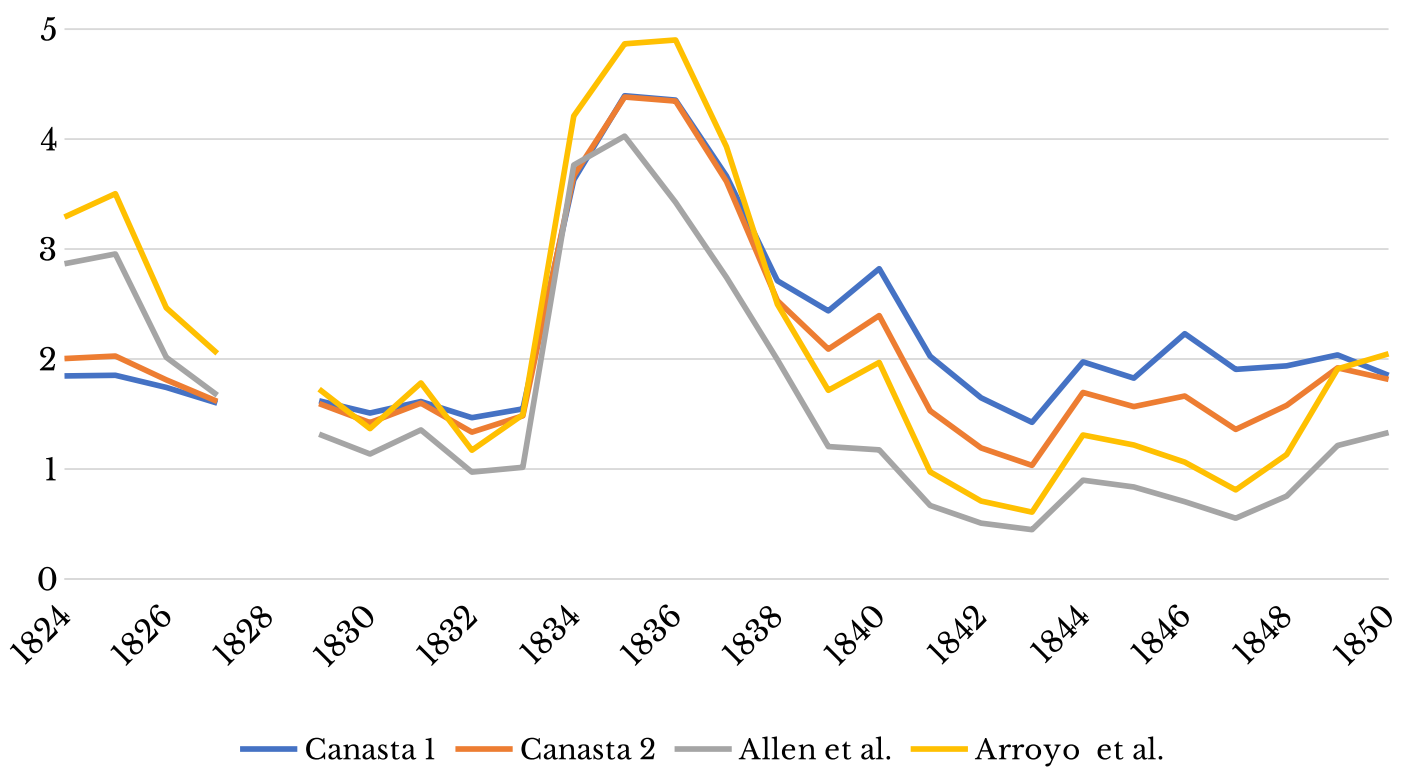

Fuente: Precios: Periódicos La Gaceta Mercantil y British Packett; véase Schmit (2020). Salarios: elaboración propia con base en Barba (1999) y Guzmán (2018). Composición de la canasta: elaboración propia con base en Gelman y Santilli (2018, tablas 7-9), Allen et al. (2012, tabla 1) y Arroyo et al. (2012, tabla 2).

Esta divergencia en los años de 1840 nos estaría señalando que, en esta economía en fuerte y sostenida expansión durante aquel decenio, más allá de las coyunturas bélicas, la demanda de mano de obra habría permitido a los trabajadores urbanos a jornal una mayor capacidad de negociación. ${ }^{16}$ En tanto que los trabajadores estatales, en momentos de suma urgencia para los ingresos públicos, registraron menores posibilidades de incremento de sus ingresos reales. ${ }^{17}$

De manera que, en términos de ventajas y desventajas, podríamos afirmar que los jornaleros tuvieron, sobre todo en coyunturas de alta demanda de trabajo, mayor poder de negociación, pero también habrían dependido mucho de la evolución de los ciclos que eran inestables en su requerimiento de cantidad de días de trabajo. En tanto los salarios públicos, en un contexto de permanente déficit fiscal, fueron modestos y en muchos lapsos estuvieron fijos. Pero, al mismo tiempo, eran labores más estables, de carga más baja en intensidad y posibles de combinar, en algunos casos, con otras actividades. Incluso podemos especular que recibieran raciones o bienes en especie co-

${ }^{16}$ Un signo elocuente del despegue de esos años son las exportaciones. La cantidad promedio de cueros vacunos (el principal ítem de exportación) que salieron por el puerto de Buenos Aires se multiplicó por dos veces y media en la década de 1840 respecto de la anterior y, en valor, el total de los bienes pecuarios exportados se multiplicó por casi dos (Rosal y Schmit, 2004).

17 Gelman y Santilli (2014) plantearon la hipótesis de que, durante las décadas de 1840 y 1850 , el crecimiento económico habría llevado a una mayor desigualdad dentro de los asalariados, por la demanda creciente de los trabajadores rurales especializados que se distancian de los empleados estatales. 
mo parte de su contrato laboral, en especial durante los momentos de aguda inflación; cuestión que es preciso indagar con nuevas fuentes. Así, este contraste nos está mostrando dos márgenes posibles de evolución del nivel de vida de los trabajadores no especializados de Buenos Aires, de forma acorde con las segmentaciones de un mercado de trabajo en formación.

En cuanto a la comparación a escala internacional, las $W R$ registradas en Buenos Aires resultan destacadas, pero de rango bastante desigual según su tipo. Así, por una parte, los jornaleros albañiles se encontraban en un nivel elevado respecto de los índices de otras ciudades europeas y latinoamericanas, como Londres, Ámsterdam, Amberes, Liepzig, Madrid, México, Bogotá o Potosí (Gelman y Santilli, 2018, tabla 14). En especial, el nivel de vida coyuntural que estimamos para el decenio de 1840 se ubica en lo alto de la escala y podría ser incluso comparable con el de algunas ciudades de Estados Unidos. Respecto de México, en particular, una diferencia notable es la tendencia a la estabilidad de la $W R$ en esa ciudad -en promedio del periodo: 2.2-2.5 (Challú y Gómez-Galvarriato, 2015)-, mientras que en Buenos Aires observamos una tendencia de crecimiento más sostenida. Esto hace que los peones de Buenos Aires igualen y superen el nivel de vida en México entre las décadas de 1830 y 1840. Por lo cual, en una visión global, esta diferencia en este segmento de trabajadores no calificados podría ser un indicador de los caminos divergentes en las economías latinoamericanas de la época posindependiente. Al mismo tiempo, esta evolución de la $W R$ permite medir la correlación con los ciclos inmigratorios de la región bonaerense. En efecto, si desde 1820 la ciudad recibía nuevos inmigrantes europeos, es claramente desde la de 1840 cuando se inicia el ciclo de la gran inmigración ultramarina, que llevaría a que, en 1855, cerca de la mitad de la población masculina fuera de origen extranjero (Massé, 2006).

No obstante, si tomamos los ingresos de los trabajadores no especializados bonaerenses vinculados a segmento estatal, los niveles de vida de los porteños serían similares a los de otros casos registrados en Sudamérica, como por ejemplo los de la ciudad de Lima (Arroyo, 2014). En ambos casos, se trata de empleados mensuales del Estado, como porteros, guardias, o sirvientes, cuyos niveles promedio de $W R$ se ubican entre 1.6-1.9 durante 1820-1850. Es de observar que, en ambas ciudades, los lapsos de mejoras coyunturales de la $W R$ (durante la década de 1830 en Buenos Aires, durante la década de 1850 en Lima) se diluyeron posteriormente como consecuencia de fuertes dinámicas inflacionarias.

\section{LISTA DE REFERENCIAS}

Aliata, F. (2006). La ciudad regular: Arquitectura, programas e instituciones en el Buenos Aires posrevolucionario, 1821-1835. Buenos Aires: Universidad Nacional de Quilmes/Prometeo Libros.

Allen, R. (2001). The Great Divergence in European Wages and Prices from the Middle Ages to the First World War. Explorations in Economic History, 38(4), 411-447. DOI: 10.1006/exeh. 2001.0775

Allen, R., Bassino, J.-P., Ma, D., Moll-Murata, C. y Van Zanden, J. (2011). Wages, prices, and living standards in China, 1738-1925: In comparison with Europe, Japan, and India. The Economic History Review, 64(s1), 8-38. DOI: 10.1111/j.1468-0289.2010.00515.x

Allen, R. C., Murphy, T. E. y Schneider, E. B. (2012). The Colonial Origins of the Divergence in the Americas: A Labor Market Approach. The Journal of Economic History, 72(4), 863-894. DOI: $10.1017 / \mathrm{S} 0022050712000629$ 
Allen, R., Murphy, T. y Schneider, E. (2015). Una de cal y otra de arena: Building Comparable Real Wages in a Global Perspective. Revista de Historia Económica/Journal of Iberian and Latin American Economic History, 33(1), 61-75. DOI: 10.1017/S0212610915000038

Amaral, S. (1988). El descubrimiento de la financiación inflacionaria. Buenos Aires, 1790-1830. Investigaciones y Ensayos, 37, 379-419.

Amaral, S. (1989). Alta inflación y precios relativos. El pago de las obligaciones en Buenos Aires (1826-1834). El trimestre económico, 56(221), 163-191.

Arroyo, A. (2013). Inestabilidad, costo de vida y salarios reales en Venezuela en el siglo xix. América Latina en la Historia Económica, 20(3), 114-137. DOI: 10.18232/alhe.v20i3.551

Arroyo, A. (2014). Failure to launch: Cost of living and living standards in Peru during the 19th Century. Revista de Historia Económica/Journal of Iberian and Latin American Economic History, 32(1), 47-76. DOI: 10.1017/S0212610913000232

Arroyo, A., Davies, E. y van Zanden, J. (2012). Between conquest and independence: Real wages and demographic change in Spanish America, 1530-1820. Explorations in Economic History, 49(2), 149-166. DOI: 10.1016/j.eeh.2011.12.001

Astorga, P., Berges, A. y Fitzgerald, V. (2005). The standard of living in Latin America during the twentieth century. The Economic History Review, 58(4), 765-796. DOI: 10.1111/j.14680289.2005.00321.x

Banzato, G. (2013). Tierras rurales: Políticas, transacciones y mercados en Argentina, 1780-1914. Rosario: Prohistoria Ediciones.

Barba, E. (1967). Notas sobre la situación económica de Buenos Aires en la década de 1820. Trabajos y Comunicaciones, 17, 65-71.

Barba, F. (1999). Aproximación al estudio de los precios y salarios en Buenos Aires desde fines del siglo XVIII hasta 1860. La Plata: Universidad Nacional de La Plata. Recuperado de http://sedici.unlp.edu. ar/handle/10915/108719

Brown, J. (2002). Historia socioeconómica de la Argentina, 1776-1860. Buenos Aires: Instituto Di Tella/Siglo Veintiuno.

Burgin, M. (1960). Aspectos económicos del federalismo argentino. Buenos Aires: Hachette.

Challú, E. y Gómez-Galvarriato, A. (2015). Mexico's real wages in the age of the great divergence, 1750s-1920s. Revista de Historia Económica/Journal of Iberian and Latin American Economic History, 33(1), 83-122. DOI: 10.1017/S021261091500004X

Cuesta, M. (2012). Precios y salarios en Buenos Aires durante la gran expansión (1850-1914). Revista de Instituciones, Ideas y Mercados, 56, 159-179.

Djenderedjian, J. (2008). La agricultura pampeana en la primera mitad del siglo XIX. Buenos Aires: Universidad de Belgrano/Siglo XXI.

Djenderedjian, J. (2013). La economía: Estructura productiva, comercio y transportes. En M. Ternavasio (Ed.), Historia de la Provincia de Buenos Aires (pp. 117-150). Buenos Aires: Edhasa/UNIPE.

Djenderedjian, J. y Martirén, J. (2015). Precios, producto agrario y niveles de vida en las fronteras rioplatenses, 1700-1810: Una nueva mirada sobre el crecimiento económico tardo-colonial. Revista de Historia Económica/Journal of Iberian and Latin American Economic History, 33(1), 123-152. DOI: 10.1017/S0212610915000051

Dobado, R. (2015). Pre-Independence Spanish Americans: Poor, Short and Unequal... Or the Opposite? Revista de Historia Económica/Journal of Iberian and Latin American Economic History, 33(1), 15-59. DOI: 10.1017/S0212610914000135 
Dobado, R. y García, H. (2014). El bienestar económico y biológico en la América borbónica: Una comparación internacional de salarios y estaturas. En J. Gelman, E. Llopis y C. Marichal (eds.), Iberoamérica y España antes de las independencias, 1700-1820: Crecimiento, reformas y crisis (pp. 481-523). México: Instituto de Investigaciones Dr. José María Luis Mora/El Colegio de México.

Eizykovicz, J. (2013). Breve historia de el pan de Buenos Aires. Buenos Aires: La Era.

Frid, C., Djenderedjian, J. y Martirén, J. L. (2018). History revenge: Discussing living standards in global comparison. The case of Rio de La Plata, 1700-1850. Presentado en Boston. Boston.

Garavaglia, J. (1999). Pastores y labradores de Buenos Aires: Una historia agraria de la campaña bonaerense 1700-1830. Buenos Aires: De la Flor.

Garavaglia, J. (2004). La economía rural de la campaña de Buenos Aires vista a través de sus precios: 1756-1852. En R. Fradkin y J. Garavaglia (eds.), En busca de un tiempo perdido: La economía de Buenos Aires en el país de la abundancia, 1750-1865 (pp. 107-158). Buenos Aires: Prometeo Libros.

Garavaglia, J. (2007). Construir el estado, inventar la nación: El Río de la Plata, siglos XVIII-XIX. Buenos Aires: Prometeo Libros.

Gelman, J. y Santilli, D. (2013). Mar de fondo. Salarios, precios y los cambios en las condiciones de vida de los pobladores de Buenos Aires en una época convulsa, 1810-1870. En D. Santilli, J. Gelman y R. Fradkin (eds.), Rebeldes con causa: Conflicto y movilización popular en la Argentina del siglo XIX (pp. 121-147). Buenos Aires, Argentina: Prometeo Libros.

Gelman, J. y Santilli, D. (2014). Los salarios y la desigualdad en Buenos Aires, 1810-1870. América Latina en la Historia Económica, 21(3), 83-115. DOI: 10.18232/alhe.v21i3.579

Gelman, J. y Santilli, D. (2018). Wages and standards of living in the 19th century from a comparative perspective. Consumption basket, Bare Bone Basket and welfare ratio in Buenos Aires, 1825-1849. Investigaciones de Historia Económica, 14(2), 94-106. DOI: 10.1016/j.ihe.2016 .09 .001

Guzmán, T. (2014). La estructura ocupacional y la economía urbana de Buenos Aires a mediados del siglo XIX, 1827-1855. Presentado en Rosario. Rosario: Asociación Argentina de Historia Económica.

Guzmán, T. (2018). Economía urbana y niFuentes: Precios: La Gaceta Mercantil y British Packett; véase Schmit (2020). Salarios: elaboración propia con base en Barba (1999) y Guzmán (2018). Composición de la canasta: elaboración propia con base en Gelman y Santilli (2018, tablas 7-9), Allen et al. (2012, tabla 1) y Arroyo et al. (2012, tabla 2).vel de vida de los trabajadores: Los salarios de los peones albañiles. Buenos Aires, 1815-1855. Presentado en La Pampa. La Pampa: Asociación Argentina de Historia Económica.

Halperin, T. (1963). La expansión ganadera en la Campaña de Buenos Aires (1810-1852). Desarrollo Económico, 3(1/2), 57-110. DOI: 10.2307/3465951

Halperin, T. (1978). Bloqueos, emisiones monetarias y precios en el Buenos Aires rosista (18381850). En F. Miró, F. Pease y D. Sobrevilla (eds.), Historia, problema y promesa: Homenaje a Jorge Basadre (pp. 307-341). Lima: Pontificia Universidad Católica del Perú.

Halperin, T. (1982). Guerra y finanzas en los orígenes del Estado argentino (1791-1850). Buenos Aires: Belgrano.

Halperin, T. (1992). Historia contemporánea de América Latina. Buenos Aires: Alianza. 
Irigoin, M. (2000). Inconvertible Paper Money, Inflation and Economic Performance in Early Nineteenth Century Argentina. Journal of Latin American Studies, 32(2), 333-359. DOI: 10.10 17/S0022216X00005769

Irigoin, M. (2004). La expansión ganadera en la campaña de Buenos Aires, 1820-1860: una consecuencia de la financiación inflacionaria del déficit fiscal. En R. Fradkin y J. Garavaglia (eds.), En busca de un tiempo perdido: La economía de Buenos Aires en el país de la abundancia, 1750-1865. Buenos Aires: Prometeo Libros.

Irigoin, M., Schmit, R. y Assadourian, C. (eds.). (2003). La desintegración de la economía colonial: Comercio y moneda en el interior del espacio colonial, 1800-1860. Buenos Aires: Biblos.

Johnson, L. (1990). Salarios, precios y costo de vida en el Buenos Aires colonial tardío. Boletín del Instituto de Historia Argentina y Americana Dr. Emilio Ravignani, 2, 133-157.

Johnson, L. (1992). La historia de precios en Buenos Aires durante el periodo virreinal. En L. Johnson y E. Tandeter (eds.), Economías coloniales: Precios y salarios en América Latina, siglo XVIII (pp. 153-190). Buenos Aires: Fondo de Cultura Económica.

Johnson, L. (2013). Los Talleres de la revolución: La Buenos Aires plebeya y el mundo del Atlántico, 1776-1810. Buenos Aires: Prometeo Libros.

Johnson, L. y Tandeter, E. (eds.). (1992). Economías coloniales: Precios y salarios en América Latina, siglo XVIII. Buenos Aires: Fstandardondo de Cultura Económica.

Katz, M. (2017). Los artesanos proteccionistas. Buenos Aires, primera mitad del siglo xIx. Economía y Política, 4(2), 5-36.

Llorca-Jaña, M. y Navarrete-Montalvo, J. (2015). The real wages and living conditions of construction workers in Santiago de Chile during the later colonial period, 1788-1808. Investigaciones de Historia Económica, 11(2), 80-90. DOI: 10.1016/j.ihe.2014.04.003

Massé, G. (2006). Inmigrantes y nativos en la ciudad de Buenos Aires al promediar el siglo xix. Población de Buenos Aires, 3(4), 9-25.

Mateo, J. (2013). La sociedad: Población, estructura social y migraciones. En M. Ternavasio (ed.), Historia de la Provincia de Buenos Aires (pp. 73-116). Buenos Aires: Edhasa/UNIPE.

Mayo, C. (ed.). (1996). Pulperos y pulperías de Buenos Aires: 1740-1830. Mar del Plata: Universidad Nacional de Mar del Plata.

Mayo, C., Fernández, Á., Bustamante, J., Cabreras, L., Duart, D., Virgili, D. y Wibaux, M. (2005). Comercio minorista y pautas de consumo en el mundo rural bonaerense 1760-1870. Anuario IEHS, 20, 239-262.

Moraes, M. I. y Thul, F. (2018). Los salarios reales y el nivel de vida en una economía latinoamericana colonial. Montevideo entre 1760-1810. Revista de Historia Económica/Journal of Iberian and Latin American Economic History, 36(2), 185-213. DOI: 10.1017/S021261091700012X

Parolo, M. (2015). Canastas de consumo y costos de subsistencia en Tucumán a mediados del siglo xix. Población y Sociedad, 22(2), 27-54.

Parolo, M. (2019). Making a living in war times. Wagesin Tucuman in the first half of the 19th Century. Quinto Sol, 23(2), 1-23. DOI: 10.19137/qs.v23i2.2708

Quiroz, E. (2016). Economía, obras públicas y trabajadores urbanos: Ciudad de México: 1687-1807. Ciudad de México: Instituto de Investigaciones Dr. José María Luis Mora.

Rosal, M. y Schmit, R. (2004). Las exportaciones pecuarias bonaerenses y el espacio mercantil rioplatense (1768-1854). En R. Fradkin y J. Garavaglia (eds.), En busca de un tiempo perdido: La economía de Buenos Aires en el país de la abundancia, 1750-1865 (pp. 159-193). Buenos Aires: Prometeo Libros. 
Sábato, H. y Romero, L. (1992). Los trabajadores de Buenos Aires: La experiencia del mercado, 18501880. Buenos Aires: Sudamericana.

Salvatore, R. (2003). Wandering paysanos: State order and subaltern experience in Buenos Aires during the Rosas era. Durham: Duke University Press.

Salvatore, R., Coatsworth, J. y Challú, A. (eds.). (2010). Living standards in Latin American history: Height, welfare, and development, 1750-2000. Cambridge: Harvard University Press.

Santilli, D. (2018). Consumption and standard of living in Buenos Aires. Consumer basket and income between the end of colonial age and the first half of XIX century. Presentado en Boston. Boston.

Santilli, D. y Gelman, J. (2016). Los estudios sobre el nivel de vida. La metodología de la canasta aplicada a la primera mitad del Siglo xix porteño. Folia Histórica del Nordeste, 26, 126-138. DOI: $10.30972 /$ fhn.026891

Schmit, R. (2013). Finanzas públicas, puerto y recursos financieros. En M. Ternavasio (ed.), Historia de la Provincia de Buenos Aires: Vol. 3: De la organización provincial a la federalización de Buenos Aires (1821-1880) (pp. 205-223). Buenos Aires: Edhasa/UNIPE. Recuperado de https://edit orial.unipe.edu.ar/colecciones/historia-de-la-provincia-de-buenos-aires/de-la-organizaci\%C 3\%B3n-provincial-a-la-federalizaci\%C3\%B3n-de-buenos-aires-1821-1880-detail

Schmit, R. (2016). Precios de bienes importados en Buenos Aires, 1824-1850. Folia Histórica del Nordeste, 26, 140-154. DOI: 10.30972/fhn.026892

Schmit, R. (2019). Prices in Buenos Aires during a cycle of war and political instability, 18251835. Quinto Sol, 23(2), 1-19. DOI: 10.19137/qs.v23i2.3478

Schmit, R. (2020). Prices and early inflation in Buenos Aires during the first half of the 19th century (1824-1850). Revista de Historia Economica/Journal of Iberian and Latin American Economic History, 38(2), 343-367. DOI: 10.1017/S0212610919000351

Stephenson, J. (2018). "Real" wages? Contractors, workers, and pay in London building trades, 1650-1800: Contractors, Workers, and Pay in London Building Trades. The Economic History Review, 71(1), 106-132. DOI: 10.1111/ehr.12491

Wibaux, M. (2004). Una mirada desde el mostrador. Dieta, hábitos alimenticios y comercio minorista en la campaña bonaerense, 1760-1870. Anuario del Centro de Estudios Históricos Profesor Carlos S. A. Segreti, (4), 125-142. DOI: 10.52885/2683-9164.v.n4.23272

Williamson, J. G. (1999). Real wages, inequality and globalization in latin america before 1940. Revista de Historia Económica/Journal of Iberian and Latin American Economic History, 17(S1), 101-142. DOI: 10.1017/S0212610900002287 